\title{
Methoxycarbonylation of Ethene by Palladium(II) Complexes with 1,1'-Bis(diphenylphosphino)ferrocene (dppf) and 1,1'-Bis(diphenylphosphino)octamethylferrocene (dppomf)
}

\author{
Claudio Bianchini,* Andrea Meli, and Werner Oberhauser \\ Istituto di Chimica dei Composti Organometallici (ICCOM-CNR), Via J . Nardi 39, \\ 50132 Firenze, Italy \\ Piet W. N. M. van Leeuwen,* Martin A. Zuideveld, Zoraida Freixa, and \\ Paul C. J . Kamer \\ Institute of Molecular Chemistry, University of Amsterdam, Nieuwe Achtergracht 166, \\ 1018 WV Amsterdam, The Netherlands \\ Anthony L. Spek \\ Department of Crystal and Structural Chemistry, Utrecht University, Padualaan 8, \\ $3584 \mathrm{CH}$ Utrecht, The Netherlands
}

Oleg V. Gusev* and Alexander M. Kal'sin

N. Nesmeyanov Institute of Organoel ement Compounds of the Russian Academy of Sciences, Vavilov St. 28, 119991 Moscow, Russian Federation

Recei ved December 27, 2002

\begin{abstract}
The square-planar bis(aquo) palladium(II) complexes $\left[\mathrm{Pd}\left(\mathrm{H}_{2} \mathrm{O}\right)_{2}(\mathrm{dppf})\right](\mathrm{OTs})_{2}$ and $\left[\mathrm{Pd}\left(\mathrm{H}_{2} \mathrm{O}\right)_{2}-\right.$ (dppomf)](OTs) 2 are effective catalysts for the methoxycarbonylation of ethene, yet they exhibit quite different selectivity: the dppf-modified catalyst produces several low molecular weight oxygenates, spanning from methyl propanoate to alternating oligomers of carbon monoxide and ethene, while the dppomf catalyst yields exclusively methyl propanoate (dppf $=1,1^{\prime}$-bis(diphenyl phosphino)ferrocene; dppomf = 1,1'-bis(diphenylphosphino)octamethylferrocene; OTs = p-toluenesulfonate). In an attempt to rationalize the different selectivities of the two catalytic systems, the methoxycarbonylation of ethene has been carried out under various experimental conditions in both autoclaves and high-pressure NMR tubes. Also, a number of model compounds have been synthesized with the aim of elucidating the structure of intermediate species observed by NMR during catalysis. Model reactions for the initiation, propagation, and chain-transfer steps in either alternating copolymerization or selective production of methyl propanoate have been performed. On the basis of all of these studies, it can be concluded that the behavior of the dppf precursor is similar to that of any other $\mathrm{Pd}$ "l catalyst modified with a chelating diphosphine. In particular, the formation of $\beta$-chelate intermediates from either $\mathrm{Pd}-\mathrm{H}$ or $\mathrm{Pd}-\mathrm{OMe}$ and their importance in controlling the perfect alternation of monomers have been experimentally demonstrated. The selective production of methyl propanoate with the use of the dppomf-modified catalyst has been attributed to the greater propensity of dppomf versus dppf to form Pd"l complexes with a dative $\mathrm{Fe}-\mathrm{Pd}$ bond, which forces the $\mathrm{P}$ atoms to be trans to each other, yielding $\mathrm{Pd}$-acyl species that do not react with ethene in $\mathrm{MeOH}$. $\beta$-Chelate species are not formed by the dppomf-modified catalyst.
\end{abstract}

\section{Introduction}

The methoxycarbonylation of ethene catalyzed by the bis(aquo) palladium(II) complexes $\left[\mathrm{Pd}\left(\mathrm{H}_{2} \mathrm{O}\right)_{2}(\mathrm{dppf})\right]-$ $(\mathrm{OTs})_{2}(\mathbf{1})$ and $\left[\mathrm{Pd}\left(\mathrm{H}_{2} \mathrm{O}\right)_{2}(\mathrm{dppomf})\right](\mathrm{OTs})_{2}$ (2) has been recently investigated by some of us (dppf $=1,1^{\prime}$-bis(diphenylphosphino)ferrocene; dppomf = 1,1'-bis(diphenylphosphino)octamethylferrocene; OTs = p-tol uenesulfonate). $^{1}$
It was found that the dppf catalyst leads to a variety of low molecular weight oxygenates spanning from methyl propanoate to perfectly alternating oligoketones, while dppomf generates a selective catalyst for methyl propanoate (Scheme 1).

(1) Gusev, O. V.; Kalsin, A. M.; Peterleitner, M. G.; Petrovskii, P. V.; Lyssenko, K. A.; Akhmedov, N. G.; Bianchini, C.; Meli, A.; Oberhauser, W. Organometallics 2002, 21, 3637. 


\section{Scheme 1}

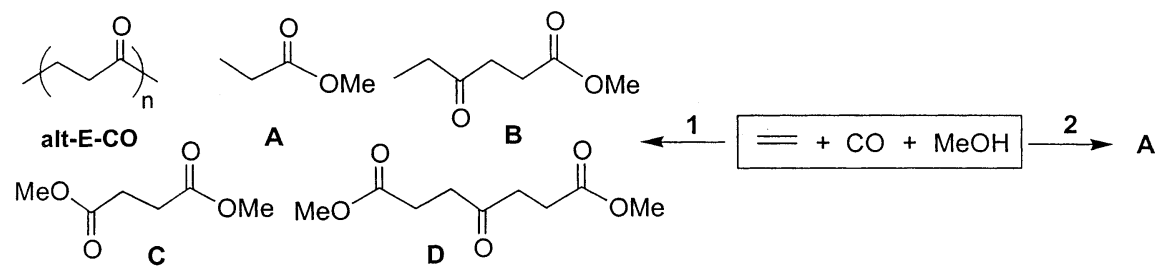

No attempt was made to rationalize the different selectivity of the two catalytic systems, apart from suggesting a correlation between chemosel ectivity and $\mathrm{P}-\mathrm{Pd}-\mathrm{P}$ bite angles in the bis(aquo) precursors. Singlecrystal X-ray analyses showed a significantly larger $\mathrm{P}-\mathrm{Pd}-\mathrm{P}$ bite angle for $\left[\mathrm{Pd}\left(\mathrm{H}_{2} \mathrm{O}\right)_{2}(\mathrm{dppomf})\right]^{2+}(101.32-$ $\left.(5)^{\circ}\right)$ as compared to $\left[\mathrm{Pd}\left(\mathrm{H}_{2} \mathrm{O}\right)_{2}(\mathrm{dppf})\right]^{2+}\left(96.38(4)^{\circ}\right) .^{1}$ Therefore, we decided to study the mechanistic aspects of the methoxycarbonylation of ethene using $\mathbf{1}$ and $\mathbf{2}$ by in situ NMR spectroscopy in conjunction with the isolation and characterization of intermediates and resting states related to catalysis. The results of this investigation are reported in this paper. We are confident to have elucidated the role of the dppf and dppomf ligands in governing the chemoselectivity of the ethene methoxycarbonylation catalyzed by $\mathbf{1}$ and $\mathbf{2}$. Our study may also contribute to a better understanding of the general mechanisms involved in the alkoxycarbonylation of ol efins ${ }^{2}$ by diphosphine-palladium(II) complexes and expand the knowledge of the coordination chemistry of $1,1^{\prime}$-bis(diorganyl phosphino)ferrocenes, ${ }^{3}$ whose applications in metal-catalyzed homogeneous reactions are increasingly numerous and successful. ${ }^{1,4}$
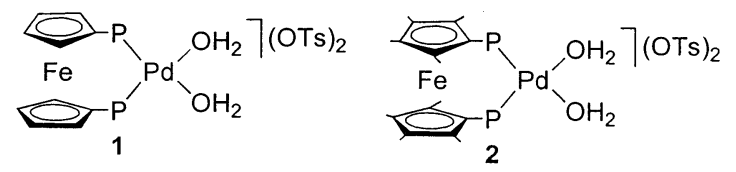

\section{Results}

Carbonylation of Ethene in Methanol with the Catalyst Precursors 1 and 2. To achieve a more profound knowledge of the catalytic activity of $\mathbf{1}$ and $\mathbf{2}$, the methoxycarbonylation of ethene with these two catalyst precursors was reinvestigated using a wider range of experimental conditions than previously done. Common to all reactions were a constant 600 psi pressure of $1: 1 \mathrm{CO} / \mathrm{C}_{2} \mathrm{H}_{4}, 85^{\circ} \mathrm{C}$, and a catalyst concentration of $10^{-4} \mathrm{M}$. Under these typical conditions, ${ }^{1,2,5} \mathbf{1}$ and $\mathbf{2}$ generated catalytic systems with almost constant activity within $1 \mathrm{~h}$ of reaction time. At longer reaction times, the conversion of ethene, estimated experimentally by measuring the gas uptake, slowed regularly, but all the systems were still active after $3 \mathrm{~h}$. Appreciable formation of inactive Pd metal, as a black powder, was observed in all reactions lasting more than $1 \mathrm{~h}$.

(2) (a) Sen, A. Acc. Chem. Res. 1993, 26, 303. (b) Drent, E. Budzelaar, P. H. M. Chem. Rev. 1996, 96, 663. (c) Drent, E.; van Broekhoven, J . A. M.; Budzelaar, P. H. M. In Applied Homogeneous Catalysis with Organometallic Compounds; Cornils, B., Herrmann, W. A., Eds.; VCH: Weinheim, 1996; Vol. 1, p 333. (d) Sommazzi, A.; Garbassi, G. Prog. Polym. Sci. 1997, 22, 1547. (e) Nozaki, K.; Hijama, T. J . Organomet. Chem. 1999, 576, 248. (f) Bianchini, C.; Meli, A. Coord. Chem. Rev. 2002, 225, 35. (g) Robertson, R. A. M.; ColeHamilton, D. J . Coord. Chem. Rev. 2002, 225, 67.
Table 1 reports data for reactions carried out in the presence of $\mathrm{p}$-toluenesulfonic acid $(\mathrm{TsOH})$ varying from 0 to 160 equiv with respect to palladium. In some reactions, the oxidant p-benzoquinone (BQ) was employed, alone or in conjunction with $\mathrm{TsOH} .{ }^{2}$ The promoting effects of protic acids and oxidants in olefin alkoxycarbonylation catalyzed by $\mathrm{Pd}^{\prime \prime}$ complexes with chelating diphosphines are well known. 2,5c,d,g Strong protic acids with weakly coordinating conjugated bases such as $\mathrm{TsOH}$ serve to remove strongly bound ligands from palladium, oxidize $\mathrm{Pd}^{0}$ species to $\mathrm{Pd}^{\prime \prime}$ species, and deliver active $\mathrm{Pd}$ "l that might have been entrapped into less active compounds, such as $\mu$-hydroxo complexes [Pd$(u-\mathrm{OH})(\mathrm{P}-\mathrm{P})]_{2}{ }^{2+}(\mathrm{P}-\mathrm{P}=$ chelating diphosphines $)$ into the catalytic cycle. The formation of the latter complexes is generally observed in reactions performed in reagent

(3) (a) Zuideveld, M. A.; Swennenhuis, B. H. G.; Boele, M. D. K.; Guari, Y.; van Strijdonck, G. P. F.; Reek, J . N. H.; Kamer, P. C. J .; Goubitz, K.; Fraanje, J .; Lutz, M.; Spek, A. L.; van Leeuwen, P. W. N. M. J . Chem. Soc., Dalton Trans. 2002, 2308. (b) Neo, Y. C.; Vittal, J. J .; Hor, T. S. A. J . Chem. Soc., Dalton Trans. 2002, 337. (c) Zuideveld, M. A.; Swennenhuis, B. H. G.; Kamer, P. C. J .; van Leeuwen, P. W. N. M. J . Organomet. Chem. 2001, 637, 805. (d) J utand, A.; Hii, (Mimi) K.-K.; Thornton-Pett, M.; Brown, J. M. Organometallics 1999, 18, 5367. (e) Yeo, J . S. L.; Vittal, J J .; Hor, T. S. A. Chem. Commun. 1999, 1477. (f) Zuideveld, M. A.; Kamer, P. C. J .; van Leeuwen, P. W. N. M.; Klusener, P. A. A.; Stil, H. A.; Roobeek, C. F. J . Am. Chem. Soc. 1998, 120, 7977. (g) Amatore, C.: Broeker, G.; J utand, A.: Khalil, F. J . Am. Chem. Soc. 1997, 119, 5176. (h) Stang, P.J .; Olenyuk, B.; Fan, J .; Arif A. M. Organometallics 1996, 15, 904. (i) Li, G.; Tan, A. L.; Yip, W.-H.; Mak, T. C. W.; Hor, T. S. A. J . Chem. Soc., Dalton Trans. 1996, 4315. (j) Fang, Z.-G.; Low, P. M. N.; Ng, S.-C.; Hor, T. S. A. J . Organomet. Chem. 1994, 483, 17. (k) Sato, M.; Shigeta, H.; Sekino, M.; Akabori, S. J . Organomet. Chem. 1993, 458, 199. (I) Dekker: G. P. C. M.; Elsevier, C. J .; Vrieze, K.; Van Leeuwen, P. W. N. M. Organometallics 1992, 11, 1598. (m) Housecroft, C. E.; Owen, S. M.; Raithby, P. R.; Shaykh, B. A. M. Organometallics 1990, 9, 1617. (n) Longato, B.; Pilloni, G.; Valle, G.; Corain, B. Inorg. Chem. 1988, 27, 956. (o) Butler, I. R. Cullen, W. R.; Kim, T.-J .; Rettig, S. J .; Trotter, J . Organometallics 1985, $4,972$.

(4) (a) Mikami, K.; Aikawa, K. Org. Lett. 2002, 4, 99. (b) Colacot, T. J . Platinum Metals Rev. 2001, 45, 22. (c) Müller, T. E.; Berger, M.; Grosche, M.; Herdtweck, E.; Schmidtchen, F. P. Organometallics 2001 20, 4384. (d) Mägerlein, W.; Indolese, A. F.; Beller, M. Angew. Chem., Int. Ed. 2001, 40, 2856. (e) Bosch, B. E.; Brümmer, I.; Kunz, K.; Erker G.; Frölich, R.; Kotila, S. Organometallics 2000, 19, 1255. (f) Ogasawara, M.; Yoshida, K.; Hayashi, T. Organometallics 2000, 19, 1567. (g) Xie, Y.; Tan, G. K.; Yan, Y. K.; Vittal, J .J .; Ng, S. C.; Hor, T. S. A.J . Chem. Soc., Dalton Trans. 1999, 773. (h) Hartwig, J . F. Angew. Chem., Int. Ed. 1998, 37, 2090. (i) Boyes, A. L.; Butler, I. R.; Quayle, S. C. Tetrahedron Lett. 1998, 39, 7763. (j) Driver, M. S.; Hartwig, J. F. J. Am. Chem. Soc. 1996, 118, 7217. (k) Hayashi, T.; Konishi, M.; Kobori, Y.; Kumada, M.; Higuchi, T.; Hirotsu, K.J . Am. Chem. Soc. 1984, 106, 158.

(5) (a) Bianchini, C.; Meli, A.; Muller, G.; Oberhauser, W.; Passaglia, E. Organometallics 2002, 21 4965. (b) Bianchini, C.; Lee, H. M.; Mantovani, G.; Meli, A.; Oberhauser, W. New J . Chem. 2002, 26, 387. (c) Bianchini, C.; Lee, H. M.; Meli, A.; Oberhauser, W.; Peruzzini, M.; Vizza, F. Organometallics 2002, 21, 16. (d) Bianchini, C.; Mantovani, G.; Meli, A.; Oberhauser, W.; Brüggeller, P.; Stampfl, T. J . Chem. Soc., Dalton Trans. 2001, 690. (e) Bianchini, C.; Lee, H. M.; Meli, A.; Oberhauser, W.; Vizza, F.; Brüggeller, P.; Haid, R.; Langes, C. Chem. Commun. 2000, 777. (f) Bianchini, C.; Lee, H. M.; Barbaro, P.; Meli, A.; Moneti, S.; Vizza, F. New J . Chem. 1999, 23, 929. (g) Bianchini, C.; Lee, H. M.; Meli, A.; Moneti, S.; Vizza, F.; Fontani, M.; Zanello, P. Macromolecules 1999, 32, 4183. (h) Bianchini, C.; Lee, H. M.; Meli, A.; Moneti, S.; Patinec, V.; Petrucci, G.; Vizza, F. Macromol ecules 1999, 32, 3859. 
Table 1. Methoxycarbonylation of Ethene Catalyzed by Pd" Complexes with dppf or Dppomf Ligandsa

\begin{tabular}{|c|c|c|c|c|c|c|c|c|}
\hline \multirow[b]{2}{*}{ entry no. } & \multirow[b]{2}{*}{ precursor } & \multirow{2}{*}{$\begin{array}{l}\text { amt of } \mathrm{TsOH} \\
\text { (equiv) }\end{array}$} & \multirow{2}{*}{$\begin{array}{l}\text { amt of BQ } \\
\text { (equiv) }\end{array}$} & \multirow{2}{*}{$\begin{array}{c}\text { alt-E-CO } \\
\text { productivity/TOF b }\end{array}$} & \multicolumn{4}{|c|}{ TOF $^{b}$} \\
\hline & & & & & A & $B$ & $C$ & $D^{e}$ \\
\hline $1^{f}$ & 1 & 0 & 0 & $110 / 214$ & 340 & 406 & 5 & 411 \\
\hline $2^{f}$ & 1 & 20 & 0 & $580 / 1069$ & 1378 & 1780 & 29 & 1887 \\
\hline 3 & 1 & $40^{c}$ & 0 & $949 / 1804$ & 2264 & 2994 & 72 & 3679 \\
\hline 4 & 1 & $80^{c}$ & 0 & $1107 / 2103$ & 2610 & 3210 & 60 & 2905 \\
\hline 5 & 1 & $160^{c}$ & 0 & $1748 / 3321$ & 2838 & 1664 & 35 & 1478 \\
\hline 6 & 1 & 0 & 80 & $263 / 500$ & 194 & 104 & 21 & 107 \\
\hline $7^{f}$ & 1 & 20 & 80 & $940 / 1785$ & 1085 & 1274 & 40 & 1280 \\
\hline 8 & $1^{d}$ & 20 & 0 & $326 / 619$ & 749 & 541 & 20 & 650 \\
\hline 9 & $1^{d}$ & 20 & 80 & $470 / 893$ & 825 & 1234 & 62 & 1851 \\
\hline 10 & 3 & 0 & 0 & traces & 69 & 23 & traces & 53 \\
\hline 11 & 3 & 20 & 0 & $338 / 643$ & 1170 & 1187 & 17 & 299 \\
\hline 12 & 3 & 0 & 80 & 0 & 171 & 79 & traces & 286 \\
\hline 13 & 3 & 20 & 80 & $376 / 714$ & 1224 & 1632 & 63 & 2210 \\
\hline $14^{f}$ & 2 & 0 & 0 & 0 & 139 & 0 & 0 & 0 \\
\hline $15^{f}$ & 2 & 20 & 0 & 0 & 550 & 0 & 0 & 0 \\
\hline 16 & 2 & 40 & 0 & 0 & 732 & 0 & 0 & 0 \\
\hline 17 & 2 & 80 & 0 & 0 & 1202 & 0 & 0 & 0 \\
\hline 18 & 2 & 160 & 0 & 0 & 1665 & 0 & 0 & 0 \\
\hline 19 & 2 & 0 & 80 & 0 & 95 & 0 & 0 & 0 \\
\hline $20^{f}$ & 2 & 20 & 80 & 0 & 513 & 0 & 0 & 0 \\
\hline 21 & $2^{d}$ & 20 & 0 & 0 & 370 & 0 & 0 & 0 \\
\hline 22 & $2^{d}$ & 20 & 80 & 0 & 460 & 0 & 0 & 0 \\
\hline 23 & 4 & 0 & 0 & 0 & 131 & 0 & 0 & 0 \\
\hline 24 & 4 & 20 & 0 & 0 & 560 & 0 & 0 & 0 \\
\hline
\end{tabular}

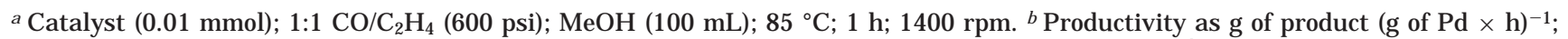
TOF as moles of ethene incorporated (moles of cat $\times \mathrm{h})^{-1}$. ${ }^{c}$ This reaction produced also diethyl ketone. ${ }^{d} 3 \mathrm{~h}$. e Three higher homologues of $\mathbf{D}$ are also included (overall $20 \%$ of $\mathbf{D}$ ). ${ }^{\mathrm{f}}$ Reference 1.

grade methanol, especially when the catalyst precursors contain water molecules, as is the case of $\mathbf{1}$ and $\mathbf{2}^{2,3 f, n, 5 a, 6}$

The organic oxidant, here $\mathrm{BQ}$, is commonly used to oxidize inactive $\mathrm{Pd}^{\prime}$ or $\mathrm{Pd}^{0}$, which may form during the catalysis, $2,5 a, d, g$ to $\mathrm{Pd}^{\prime \prime}$ and also transform (P-P)Pd ${ }^{\prime \prime}-\mathrm{H}$

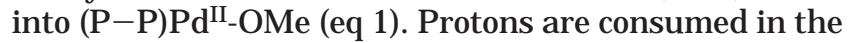
course of the latter process.

$$
\begin{gathered}
\left.[(\mathrm{P}-\mathrm{P}) \mathrm{PdH}]^{+} \rightleftharpoons[\mathrm{P}-\mathrm{P}) \mathrm{Pd}\right]^{0}+\mathrm{H}^{+} \frac{\mathrm{O}=\mathrm{MeOH}}{[(\mathrm{P}-\mathrm{P}) \mathrm{Pd}(\mathrm{OMe})]^{+}+\mathrm{HO}-\mathrm{O}} \\
\longrightarrow-\mathrm{OH}
\end{gathered}
$$

The catalytic activities of $\mathbf{1}$ and $\mathbf{2}$ increased steadily with the TsOH concentration with no significant change in the chemoselectivity up to 80 equiv of acid (entries 1-4 and 14-17). The dppf-based catalysts gave several carbonylation products (Scheme 1), from alternating oligoketones (alt-E-CO) to a variety of low molecular weight oxygenates including methyl propanoate (A), methyl 4-oxohexanoate (B), dimethyl succinate (C), and dimethyl 4-oxoheptanedioate (D). Three other oligomeric diesters with higher molecular weight were also detected by GC in small amounts (overall $20 \%$ of D). In contrast, the dppomf-based catalyst produced $\mathbf{A}$ exclusively. I rrespective of the reaction conditions, the overall TOFs (moles of ethene incorporated (moles of cat $\times h)^{-1}$ ) obtained with the dppf-modified catalysts were significantly higher than those with dppomf.

In the case of $\mathbf{1}$, the production of diethyl ketone was observed under acidic conditions only, with a maximum TOF of 190 in the presence of 160 equiv of $\mathrm{TsOH}$. The addition of BQ decreased the activity of $\mathbf{1}$ (entries 6 and 7 vs 1 and 2), yet the organic oxidant improved the selectivity in alt-E-CO as well as the catalyst stability, as is evident from a comparison between reactions lasting $1 \mathrm{~h}$ (entries 2 and 7) and $3 \mathrm{~h}$ (entries 8 and 9).
Some reactions were also carried out using the $\mu$-hydroxo complex $[\mathrm{Pd}(\mu-\mathrm{OH})(\mathrm{dppf})]_{2}(\mathrm{OTs})_{2}$ (3), which was shown to be a chain-transfer product by in situ HPNMR spectroscopy (see below). ${ }^{3 f, n}$ Complex $\mathbf{3}$ generated an effective catalyst only in the presence of $\mathrm{TsOH}$ as co-reagent (entry 11), while the concomitant presence of both acid and organic oxidant gave an overall TOF that was almost twice as high. Recent studies have shown that $\mu$-hydroxo $\mathrm{Pd}^{\prime \prime}$ complexes with chelating diphosphines are active catalyst precursors for the alternating $\mathrm{CO} / \mathrm{C}_{2} \mathrm{H}_{4}$ copolymerization due to their capability to react with $\mathrm{CO}$, forming mononuclear $\mathrm{Pd}^{\prime \prime}{ }_{-} \mathrm{H}$ moieties via a water gas shift mechanism. ${ }^{5 a, 7}$

In the absence of $\mathrm{BQ}$, with or without $\mathrm{TsOH}$, the oligoketone products were featured by a $1: 1$ ratio between ketone and ester end groups and an average molecular weight of ca. $0.5 \mathrm{~kg} \mathrm{~mol}^{-1}\left({ }^{1} \mathrm{H}\right.$ and ${ }^{13} \mathrm{C}\left\{{ }^{1} \mathrm{H}\right\}$ NMR analysis). When BQ was used in conjunction with the acid (entry 7), a slight prevalence of ester over ketone end groups (6:4 ratio) was observed (molecular weight of $0.6 \mathrm{~kg} \mathrm{~mol}^{-1}$ ), while, in the presence of 80 equiv of BQ with no added acid (entry 6), the end groups were prevalently constituted by ester groups (8:2 ratio) and the average molecular weight was $0.7 \mathrm{~kg} \mathrm{~mol}^{-1}$.

Like observed for $\mathbf{1}$, the catalytic activity of $\mathbf{2}$ did not improve by using BQ as co-reagent (entries 19, 20), yet the presence of the organic oxidant improved the catalyst stability (entries 15, 20 vs entries 21,22 ).

The last two entries of Table 1 refer to reactions performed with the catalyst precursor $\left[\mathrm{Pd}_{2}(\mu-\mathrm{H})(\mu-\mathrm{CO})\right.$ (dppomf) $)_{2}$ ]OTs (4), which was actually intercepted by NMR spectroscopy during the methoxycarbonylation

(6) (a) Ledford, J .; Shultz, C. S.; Gates, D. P.; White, P. S.; DeSimone, J. M.; Brookhart, M. Organometallics 2001, 20, 5266. (b) Pisano, C.; Consiglio, G. Gazz. Chim. Ital. 1994, 124, 393. (c) Pisano, C.; Consiglio, G.; Sironi, A.; Moret, M. J . Chem. Soc., Chem. Commun. 1991, 421.

(7) Verspui, G.; Schanssema, F.; Sheldon, R. A. Appl. Catal. A: Gen. 2000, 198, 5 . 


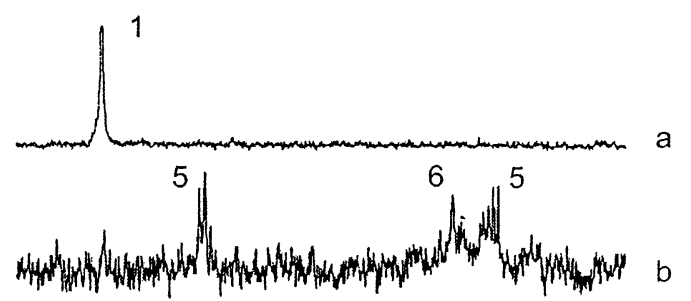

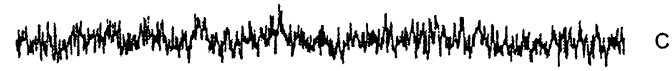

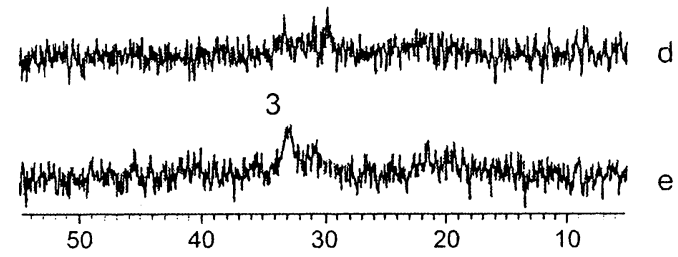

Figure 1. Variable-temperature ${ }^{31} \mathrm{P}\left\{{ }^{1} \mathrm{H}\right\}$ NMR study (sapphire tube, $\mathrm{MeOH}-\mathrm{d}_{4}, 81.01 \mathrm{MHz}$ ) of the carbonylation reaction of ethene catalyzed by $\mathbf{1}$ : (a) dissol ving $\mathbf{1}$ in $\mathrm{MeOH}$ $\mathrm{d}_{4}$ under nitrogen at room temperature; (b) after the tube was pressurized with 40 bar of $\mathrm{CO} / \mathrm{C}_{2} \mathrm{H}_{4}(1: 1)$ at room temperature; (c) after $10 \mathrm{~min}$ at $50{ }^{\circ} \mathrm{C}$; (d) after $10 \mathrm{~min}$ at $70{ }^{\circ} \mathrm{C}$; (e) after the tube was cooled to room temperature.

Chart 1. Complexes Seen in the HPNMR Study of the Methoxycarbonylation of Ethene Catalyzed by 1

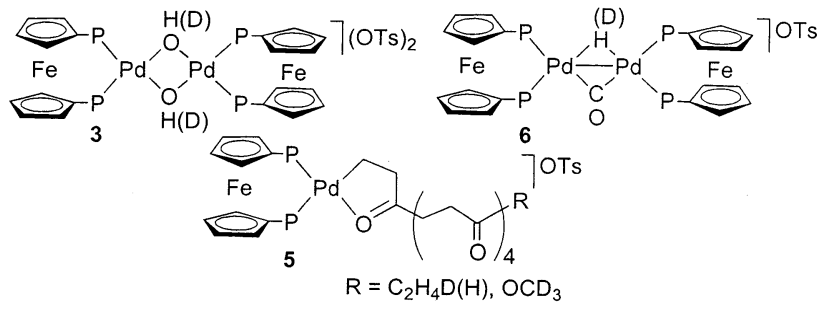

reactions catalyzed by $\mathbf{2}$ (see below). ${ }^{6 b, 8-12}$ Precursor 4 was as efficient and selective as the parent complex $\mathbf{2}$ under comparable experimental conditions. A few reports showing a catalytic role for $\mu-\mathrm{H}(\mu-\mathrm{CO}) \mathrm{Pd}$ complexes in alkene carbonylation reactions have appeared in the relevant literature. $6 \mathrm{~b}, 8 \mathrm{~b}$

In Situ High-Pressure NMR Study of the Methoxycarbonylation of Ethene Catalyzed by $\mathbf{1}$. The reaction catalyzed by $\mathbf{1}$ was followed by variabletemperature ${ }^{31} \mathrm{P}\left\{{ }^{1} \mathrm{H}\right\}$ and ${ }^{1} \mathrm{H}$ HPNMR spectroscopy in $\mathrm{MeOH}-\mathrm{d}_{4}$. A sequence of selected ${ }^{31} \mathrm{P}\left\{{ }^{1} \mathrm{H}\right\} \mathrm{NMR}$ spectra is reported in Figure 1 .

A $10 \mathrm{~mm}$ sapphire HPNMR tube was charged under nitrogen with a solution of $\mathbf{1}$ in $\mathrm{MeOH}-\mathrm{d}_{4}$ and then placed into the NMR probe at room temperature $(\delta 47.9$, trace a). Pressurizing with a $1: 1$ mixture of $\mathrm{CO} / \mathrm{C}_{2} \mathrm{H}_{4}$ to 40 bar at room temperature (trace b) converted 1 into the $\beta$-chelate complexes $\left[\mathrm{Pd}\left(\mathrm{CH}_{2} \mathrm{CH}_{2} \mathrm{C}(\mathrm{O})\left(\mathrm{CH}_{2} \mathrm{CH}_{2} \mathrm{C}\right.\right.\right.$ $\left.(\mathrm{O}))_{n} \mathrm{R}\right)(\mathrm{dppf})$ ]OTs (5; doublets at ca. $\delta 40$ and 16 with $\mathrm{J}(\mathrm{PP})$ of ca. $36 \mathrm{~Hz}$ ) (Chart 1). R in 5 may be either $\mathrm{OCD}_{3}$ or $\mathrm{C}_{2} \mathrm{H}_{4} \mathrm{D}(\mathrm{H})$ depending on whether the reaction starts with $\mathrm{Pd}-\mathrm{D} / \mathrm{H}$ or $\mathrm{Pd}-\mathrm{OCD}_{3}$, respectively. The average repeating units of the chain in $\mathbf{5}$ were estimated to be

(8) (a) Siedle, A. R.; Newmark, R. A.; Gleason, W. B. Inorg. Chem. 1991, 30, 2005. (b) Zudin, V. N.; Chinakov, V. D.; Nekipelov, V. M.; Rogov, V. A.; Likholobov, V. A.; Yermakov, Yu. I. J . Mol. Catal. 1989, $52,27$. ca. 4 by ${ }^{1} \mathrm{H}$ NMR integration. 2,3f,5c,12-19 A minor species (5-10\%) featured by a broad signal at $\delta 19.6$ was also observed that was assigned to the $\mu$-hydrido- $\mu$-carbonyl complex $\left[\mathrm{Pd}_{2}(u-\mathrm{D} / \mathrm{H})(u-\mathrm{CO})(\mathrm{dppf})_{2}\right] \mathrm{OTs}(6)$ (Chart 1). ${ }^{6 \mathrm{~b}, 8-12}$ In addition to the formation of these well-defined species, appreciable catalyst degradation occurred, as shown by the high noise level of the baseline and the appearance of traces of black palladium in the NMR tube. The ${ }^{1} \mathrm{H}$ NMR spectrum of $\mathbf{6}$ contained a weak, yet unambiguously identifiable signal due to the $\mu-\mathrm{H}$ hydrogen (quintet at $\delta-6.01$ ), which suggests the involvement of the water molecules contained in both $\mathbf{1}$ and solvent in the formation of $\mathrm{Pd}-\mathrm{H}$ moieties. Alternatively, the proton may stem from $\mathrm{H} / \mathrm{D}$ scrambling with ethene via $\beta$-hydride el imination of palladium alkyl intermediates. Increasing the temperature led to the disappearance of $\mathbf{5}$ and 6; species in fast dynamic exchange were formed in their place (see the spectra recorded in the temperature range from 50 to $70{ }^{\circ} \mathrm{C}$, traces $\mathrm{c}$ and $\mathrm{d}$ ). After $30 \mathrm{~min}$ at $70{ }^{\circ} \mathrm{C}$, the probe-head was cooled to room temperature. The ${ }^{31} \mathrm{P}\left\{{ }^{1} \mathrm{H}\right\}$ NMR spectrum at this temperature showed the formation of a mixture of products that denied first-order analysis. The only complex that we could assign was the known $\mu$-OH(OD) complex 3 (Chart 1) (trace e, singlet at $\delta 33.1$ ). ${ }^{3 f, n}$ Analysis of the solution by GC showed the formation of deuterated samples of $\mathbf{A}, \mathbf{B}, \mathbf{C}$, and $\mathbf{D}$. The formed cooligomer was similar to the samples obtained in the batch experiments under comparable experimental conditions with ñ values of ca. 8 and both ketonic and ester end groups. ${ }^{1}$

A different ${ }^{31} \mathrm{P}\left\{{ }^{1} \mathrm{H}\right\}$ NMR picture was observed when the methoxycarbonylation of ethene was performed in the presence of 16 equiv of $\mathrm{BQ}$ with respect to the catalyst. In this case the $\mathrm{Pd}^{\prime}-\mathrm{Pd}^{\prime}$ complex $\mathbf{6}$ did not form at any stage of the reaction, while the $\mu$-OH species was again seen at the end of the reaction. Along the whole experiment, the spectral noise was much lower than that observed in the absence of oxidant, which reflects a minor degradation of the $\mathrm{Pd}^{\text {Il }}$ catalyst to palladium metal.

In the reaction performed in the presence of 4 equiv of $\mathrm{TsOH}$, no other palladium complex than $\mathbf{1}$ was seen by NMR spectroscopy, besides the protonolysis termination product 3. ${ }^{3 f}$ Moreover, the signal of the precursor 1 persisted up to $50{ }^{\circ} \mathrm{C}$. Apparently, the formation of the $\beta$-chelates 5 from either $\mathrm{Pd}$-H or $\mathrm{Pd}$-OMe is inhibited at room temperature by the tosylate ions, which may compete with monomers for coordination to palladium. Above $50{ }^{\circ} \mathrm{C}$, when the methoxycarbonylation products started to form, all the species were in rapid chemical exchange on the NMR time scale and therefore undetectable.

Synthesis and Characterization of Intermediates and Resting States in the Methoxycarbonylation of Ethene Catalyzed by $\mathbf{1}$. The model $\beta$-chelate complex $\left[\mathrm{Pd}\left(\mathrm{CH}_{2} \mathrm{CH}_{2} \mathrm{C}(\mathrm{O}) \mathrm{Me}\right)(\mathrm{dppf})\right] \mathrm{OTf} \mathrm{Tf}^{32}$ (7) was synthesized by sequential bubbling of $\mathrm{CO}$ and ethene into a solution of [PdMe(NCMe)(dppf)]OTf ${ }^{3 l}$ in $\mathrm{CH}_{2} \mathrm{Cl}_{2}$

(9) (a) Perez, P. J ; Calabrese J . C.; Bunel, E. E. Organometallics 2001, 20, 337. (b) Portnoy, M.; Milstein, D. Organometallics 1994, 13, 600. (c) Portnoy, M.; Frolow, F .; Milstein, D. Organometallics 1991, $10,3960$.

(10) Tóth, I.; Elsevier: C. J . Organometallics 1994, 13, 2118. 


\section{Scheme 2}

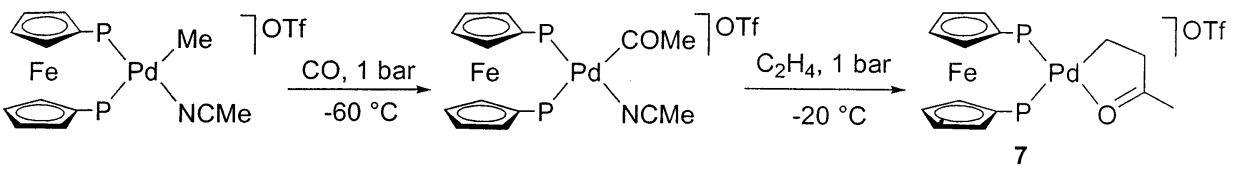

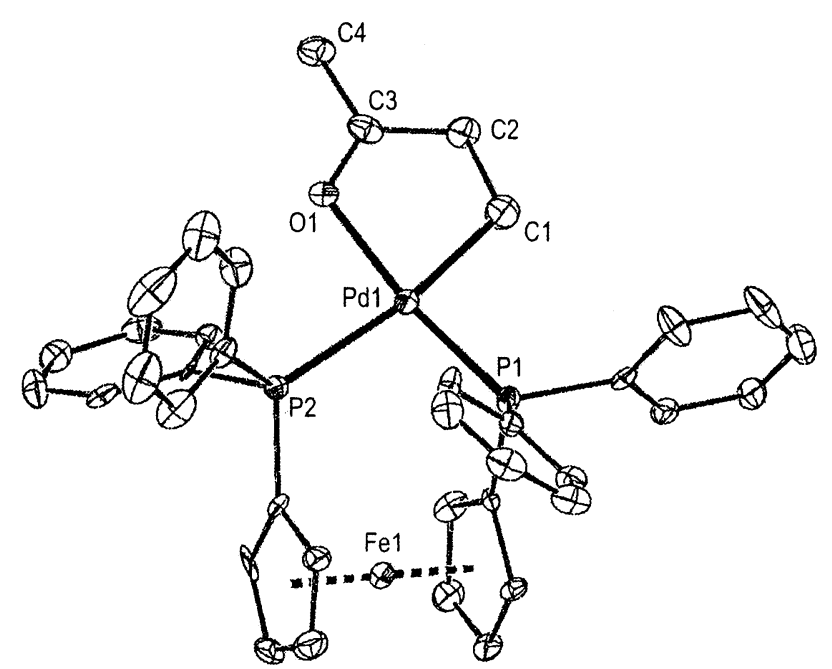

Figure 2. ORTEP drawing (30\% displacement ellipsoids) of the cation of $\mathbf{7} \cdot 0.5 \mathrm{CH}_{2} \mathrm{Cl}_{2}$. Hydrogen atoms, triflate anion, and $\mathrm{CH}_{2} \mathrm{Cl}_{2}$ have been omitted for clarity.

Table 2. Selected Geometrical Parameters for $7 \cdot 0.5 \mathrm{CH}_{2} \mathrm{Cl}_{2}$

\begin{tabular}{cccc}
\hline \multicolumn{2}{c}{ bond lengths $(\AA)$} & \multicolumn{2}{c}{ bond angles (deg) } \\
\hline $\mathrm{Pd}-\mathrm{P} 1$ & $2.220(3)$ & $\mathrm{P} 1-\mathrm{Pd}-\mathrm{P} 2$ & $98.47(9)$ \\
$\mathrm{Pd}-\mathrm{P} 2$ & $2.395(3)$ & $\mathrm{P} 2-\mathrm{Pd}-\mathrm{O} 1$ & $89.9(2)$ \\
$\mathrm{Pd}-\mathrm{O} 1$ & $2.123(7)$ & $\mathrm{P} 1-\mathrm{Pd}-\mathrm{C} 1$ & $90.5(3)$ \\
$\mathrm{Pd}-\mathrm{C} 1$ & $2.032(12)$ & $\mathrm{O} 1-\mathrm{Pd}-\mathrm{C} 1$ & $81.1(4)$ \\
$\mathrm{C} 1-\mathrm{C} 2$ & $1.490(15)$ & $\mathrm{O} 1-\mathrm{C} 3-\mathrm{C} 2$ & $119.9(9)$ \\
$\mathrm{C} 2-\mathrm{C3}$ & $1.476(16)$ & $\mathrm{O} 1-\mathrm{C} 3-\mathrm{C} 4$ & $119.5(10)$ \\
$\mathrm{C} 3-\mathrm{C} 4$ & $1.466(14)$ & $\mathrm{Pd}-\mathrm{O} 1-\mathrm{C} 3$ & $114.1(7)$ \\
$\mathrm{C} 3-\mathrm{O} 1$ & $1.229(13)$ & $\mathrm{C} 1-\mathrm{C} 2-\mathrm{C} 3$ & $113.3(10)$ \\
& & $\mathrm{Pd}-\mathrm{C} 1-\mathrm{C} 2$ & $110.3(8)$
\end{tabular}

at low temperature, followed by solvent evaporation (Scheme 2).

The coordination of the $\beta$-keto group was inferred by the low-field ${ }^{13} \mathrm{C}\left\{{ }^{1} \mathrm{H}\right\}$ NMR signal of the carbonyl carbon atom $(\delta$ 238.9) and the low-frequency $v(C O)$ stretch $\left(1630 \mathrm{~cm}^{-1}\right) .{ }^{15-19}$ Conclusive evidence of the $\beta$-chelate structure was obtained by a single-crystal X-ray analysis of $7 \cdot 0.5 \mathrm{CH}_{2} \mathrm{Cl}_{2}$ (Figure 2 and Table 2).

The structure consists of $\left[\mathrm{Pd}\left(\mathrm{CH}_{2} \mathrm{CH}_{2} \mathrm{C}(\mathrm{O}) \mathrm{Me}\right)(\mathrm{dppf})\right]^{+}$ complex cations and triflate counteranions with interspersed $\mathrm{CH}_{2} \mathrm{Cl}_{2}$ molecules. The metal center exhibits a

(11) Sperrle, M.; Gramlish, V.; Consiglio, G. Organometallics 1996, $15,5196$.

(12) Zuideveld, M. A. Thesis, University of Amsterdam, 2001.

(13) Dekker, G. P. C. M.; Elsevier, C. J .; Vrieze, K.; van Leeuwen, P. W. N. M.; Roobeek, C. F. J . Organomet. Chem. 1992, 430, 357

(14) (a) Ozawa, F.; Hayashi, T.; Koide, H.; Yamamoto, A. J . Chem. Soc., Chem. Commun. 1991, 1469. (b) Reddy, K. R.; Surekha, K.; Lee, G.-H.; Peng, S.-M.; Chen, J.-T.; Liu, S.-T. Organometalllics 2001, 20, 1292.

(15) Shultz, C. S.; Ledford, J .; DeSimone, J . M.; Brookhart, M. J . Am. Chem. Soc. 2000, 122, 6351

(16) Rix, F. C.; Brookhart, M. J . Am. Chem. Soc. 1995, 117, 1137. (17) Parlevliet, F. J .; Zuideveld, M. A.; Kiener, C.; Kooijman, H.; Spek, A. L.; Kamer, P. C. J .; van Leeuwen, P. W. N. M. Organometallics 1999, 18, 3394.

(18) Aeby, A.; Consiglio, G. J . Chem. Soc., Dalton Trans. 1999, 655.

(19) Green, M. J .; Britovsek, G. J . P.; Cavell, K.J .; Skelton, B. W.; White, A. H. J . Chem. Soc., Chem. Commun. 1996, 1563. square-planar geometry with cis coordinating phosphorus atoms (P1-Pd-P2 angle of $\left.98.47(9)^{\circ}\right)$. This $\mathrm{P} 1-\mathrm{Pd}-$ P2 angle is similar to that of other palladium complexes of dppf. ${ }^{20}$ The structure shows the chelate ring with the oxygen atom of the carbonyl group coordinated to the metal center. The $\mathrm{Pd}-\mathrm{Pl}$ distance is much shorter $(2.220(3) \AA$ ) than the Pd-P2 distance (2.395(3) $\AA$ ), as this bond is trans-located to the Pd-alkyl bond, whereas the $\mathrm{P} 2$ phosphorus is trans-coordinated to the coordinating oxygen atom. The Pd-O bond length of 2.123(4) $\AA$ is in accordance with a dative bond. ${ }^{19,21}$

The (carbonyl)acyl complex $\left[\mathrm{Pd}(\mathrm{CO})\left(\mathrm{C}(\mathrm{O}) \mathrm{CH}_{2} \mathrm{CH}_{2} \mathrm{C}\right.\right.$ (O)Me)(dppf)]OTf (8) and the $\beta$-ketoalkyl derivative [Pd$\left(\mathrm{CH}_{2} \mathrm{CH}_{2} \mathrm{C}(\mathrm{O}) \mathrm{CH}_{2} \mathrm{CH}_{2} \mathrm{C}(\mathrm{O}) \mathrm{Me}\right.$ (dppf)]OTf (9) were pre pared in $\mathrm{CD}_{2} \mathrm{Cl}_{2}$ and characterized by NMR spectroscopy at low temperature. The reaction of $\mathrm{CO}$ with $\mathbf{7}$ gave the carbonyl (acyl) 8, which was transformed into the $\beta$-chelate $\mathbf{9}$ by reaction with ethene (Scheme 3). In the reaction leading to $\mathbf{9}$, the formation of a minor species featured by two doublets with chemical shifts and coupling constants ( $\delta 39.1$ and 15.4, 2 $(P P)=35.8 \mathrm{~Hz}$ ) very close to those of $\mathbf{9}$ ( $\delta 38.7$ and 15.8, ${ }^{2}$ ) $(\mathrm{PP})=35.7$ $\mathrm{Hz}$ ) was observed. On the basis of these NMR data and the presence of two IR bands at 1629 and $1710 \mathrm{~cm}^{-1}$, which are typical of coordinated and free carbonyl groups, respectively, ${ }^{22}$ we suggest that this minor species is a higher $\beta$-ketoalkyl homologue of $\mathbf{9}$ formed by reaction of the latter with residual $\mathrm{CO}$ and ethene in the solution.

Multinuclear NMR analysis allowed for the identification of the acyl (carbonyl) complex 8; in particular, the ${ }^{13} \mathrm{C}\left\{{ }^{1} \mathrm{H}\right\}$ NMR spectrum showed an acyl carbon signal at $\delta 229.3(\mathrm{~d}, 2 \mathrm{~J}(\mathrm{CP})=86.7 \mathrm{~Hz})$ and ketone carbon signal at $\delta 208.1$ (s).

The $\mu-\mathrm{H}, \mu$-CO complex 6 was independently synthesized by two different methods, involving either the treatment of the aquo complex $\mathbf{1}$ with $\mathrm{CO}$ in $\mathrm{CH}_{2} \mathrm{Cl}_{2}$ (water-gas shift reaction) ${ }^{2}$ (route a in Scheme 4) or the methanolysis of the Pd-acetyl complex [Pd(COMe)(NCMe)(dppf)]OTs ${ }^{3 l}$ under a CO atmosphere (route b). The NMR features of $\mathbf{6}$ are in line with those of other $\mu$-hydrido, $\mu$-carbonyl binuclear $\mathrm{Pd}^{8-12}$ and $\mathrm{Pt}^{23}$ complexes stabilized by phosphine ligands.

The synthesis of $\mathbf{6}$ from an acetyl complex in the presence of $\mathrm{CO}$ (route b) resembles closely the chaintransfer mechanism by methanolysis in real copolymerization reactions catalyzed by $\mathrm{Pd}^{\prime \prime}$ precursors with chelating diphosphines where the acetyl group is sub-

(20) Dierkes, P.; van Leeuwen, P. W. N. M. J . Chem. Soc., Dalton Trans. 1999, 1519.

(21) Reddy, K. R.; Chen, C.-L.; Hung Liu, Y.-H.; Peng, S.-M.; Chen, .-T.; Liu, S.-T. Organometalllics 1999, 18, 2574

(22) Mul, W. P.; Oosterbeek, H.; Beitel, G. A.; Kramer, G.-J .; Drent, E. Angew. Chem., Int. Ed. 2000, 39, 1848.

(23) (a) Minghetti, G.; Bandini, A. L.; Banditelli, G.; Bonati, F. Szostak, R.; Strouse, C. E.; Knobler, C. B.; Kalst, H. D. Inorg. Chem. 1983, 22, 2332. (b) Bandini, A. L.; Banditelli, G.; Cinellu, M. A.; Sanna, G.; Minghetti, G.; Demartin, F.; Manassero, M. Inorg. Chem. 1989, 28, 404. (c) Bandini, A. L.; Banditelli, G.; Demartin, F.; Manassero, M.; Minghetti, G. Gazz. Chim. Ital. 1993, 123, 417. 


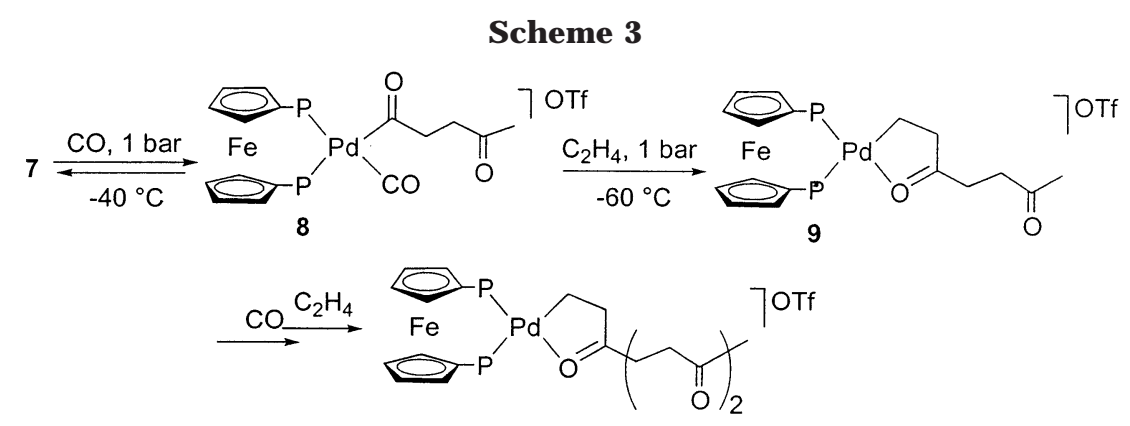

Scheme 4

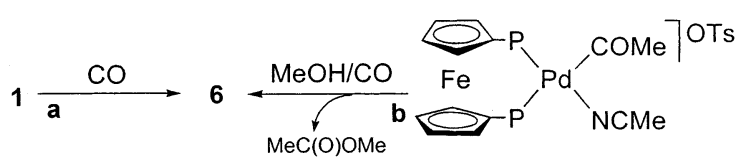

Scheme 5

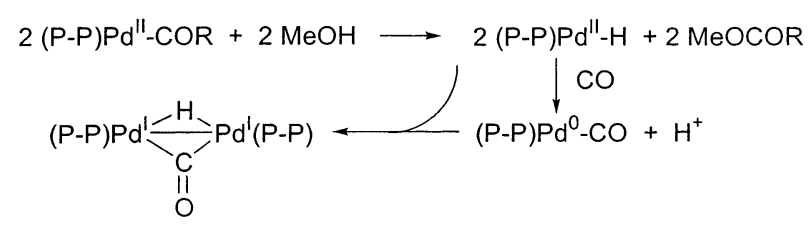

Scheme 6

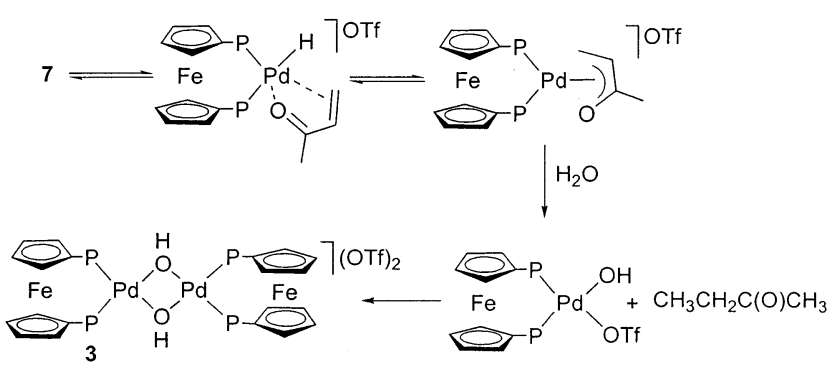

stituted by a generic acyl group (Scheme 5). ${ }^{2}$ Following the methanolysis of Pd-COR with production of the corresponding ester, the resultant $\left[\mathrm{Pd} \mathrm{I}^{\prime \prime} \mathrm{H}(\mathrm{P}-\mathrm{P})\right]$ fragment is not stable in the presence of $\mathrm{CO}^{2,9 a, 24} \mathrm{Part}$ of it disproportionates to give $\mathrm{H}^{+}$and $\left[\mathrm{Pd}^{0}(\mathrm{CO})(\mathrm{P}-\mathrm{P})\right]$. The combination of the latter $\mathrm{Pd}^{0}$ fragment with residual $\left[P d^{\prime \prime} H(P-P)\right]$ eventually generates the $P d^{\prime}-P d^{\prime} \mu-H$, $\mu$-CO species.

The $\mu$-OH complex $\mathbf{3}$ was previously synthesized by Longato ${ }^{3 n}$ and later shown by van Leeuwen to be the chain-transfer product by protonolysis with water in $\mathrm{CO} /$ $\mathrm{C}_{2} \mathrm{H}_{4}$ copolymerizations catalyzed by $\mathrm{Pd}^{\prime \prime}$-dppf complexes. ${ }^{3 f}$ The formation of $\mathbf{3}$ involves $\beta$-chelates, structurally similar to $\mathbf{6}$, that isomerize to enolates prior to undergoing regioselective attack by water at the $C_{2}$ carbon atom. This mechanism is exemplified for $\mathbf{7}$ in Scheme 6. ${ }^{3 f}$

Stability of 2 in Methanol. Synthesis and Characterization of $\left[\mathbf{P d}(\mathbf{d p p o m f})_{\mathbf{2}}(\mathrm{OTs})_{2}\right.$. The starting solution employed in this study was obtained by dissolving a sample of $\mathbf{2}$ in $\mathrm{MeOH}-\mathrm{d}_{4}$ at room temperature. Within a few minutes, the green solution of $\mathbf{2}$ turned brownish red. The reaction was followed by ${ }^{31} \mathrm{P}\left\{{ }^{1} \mathrm{H}\right\}$ and ${ }^{1} \mathrm{H}$ NMR spectroscopy. The first ${ }^{31} \mathrm{P}\left\{{ }^{1} \mathrm{H}\right\}$ NMR spectrum showed a $14 \%$ conversion of the precursor $(\delta 71.6)$ into

(24) Di Bugno, C.; Pasquali, M.; Leoni, P.; Sabatino, P.; Braga, D. Inorg. Chem. 1989, 28, 1390.

\section{Chart 2. Complexes Seen in the HPNMR Study of the Methoxycarbonylation of Ethene Catalyzed by 2}

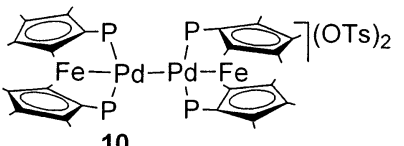

10
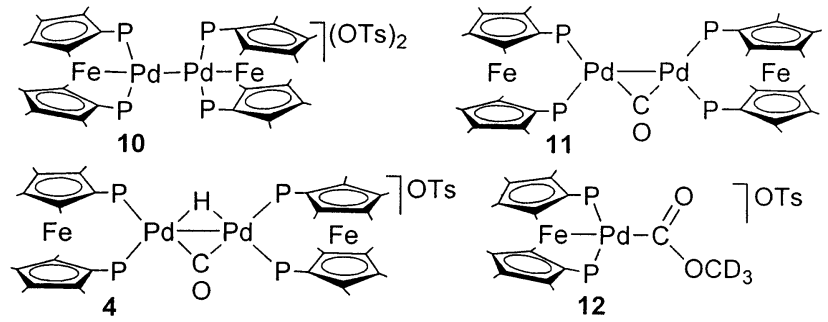

the palladium(I) binuclear complex $[\mathrm{Pd}(\mathrm{dppomf})]_{2}(\mathrm{OTs})_{2}$ (10) $(\delta-1.3)$ (Chart 2). ${ }^{11,25,26}$ Additional NMR spectra were acquired every $30 \mathrm{~min}$ at room temperature. The ratio between $\mathbf{2}$ and $\mathbf{1 0}$ did not appreciably vary with time, yet the concentration of these two compounds slowly decreased, becoming, altogether, one-fifth of the initial one over 2 days. The ${ }^{1} \mathrm{H}$ NMR spectra acquired during this experiment showed a small downfield shift of the resonances of both p-toluenesulfonate ions and adventitious water, which is consistent with the presence of protons in solution (vide infra). In separate NMR experiments, treating a freshly prepared solution containing $\mathbf{2}$ and $\mathbf{1 0}$ with 4 equiv of either $\mathrm{TsOH}$ or $\mathrm{BQ}$ resulted in re-formation of $\mathbf{2}$ as the exclusive complex.

In Situ High-Pressure NMR Study of the Methoxycarbonylation of Ethene Catalyzed by 2 without Co-reagent. A $10 \mathrm{~mm}$ sapphire HPNMR tube was charged under nitrogen with a solution prepared by dissolving a solid sample of $\mathbf{2}$ in $\mathrm{MeOH}-\mathrm{d}_{4}$ and then placed into the NMR probe at room temperature. A sequence of selected ${ }^{31} \mathrm{P}\left\{{ }^{1} \mathrm{H}\right\}$ NMR spectra is reported in Figure 3.

As already observed in the stability study of $\mathbf{2}$ in methanol, the first spectrum (trace a) showed the partial conversion (15\%) of the precursor into $\mathbf{1 0}$. The NMR tube was pressurized with a $1: 1$ mixture of $\mathrm{CO} / \mathrm{C}_{2} \mathrm{H}_{4}$ to 40 bar at room temperature (trace b) and then heated to $40{ }^{\circ} \mathrm{C}$. As shown by the first spectrum acquired at this temperature (trace c), both complexes converted into a new complex featured by a singlet at $\delta 5.6$, which we suggest to be the $\mathrm{Pd}^{0} \mu-\mathrm{CO}$ binuclear complex $\mathrm{Pd}_{2}-$ $(u$-CO)(dppomf) 2 (11) (Chart 2) on the basis of its NMR characteristics (see below). ${ }^{27}$ Increasing progressively the temperature to 50 (trace d), 60 (trace e), and $70{ }^{\circ} \mathrm{C}$ (trace f) decreased the concentration of 11; in its place

(25) Budzelaar, P. H. M.; van Leeuwen, P. W. N. M.; Roobeek, C. F . Organometallics 1992, 11, 23.

(26) Davies, J . A.; Hartley, F. R.; Murray, S. G.; Marshall, G. J . Mol . Catal. 1981, 10, 171.

(27) Trebbe, R.; Goddard, R.; Rufinska, A.; Seevogel, K.; Porschke, K.-R. Organometallics 1999, 18, 2466. 


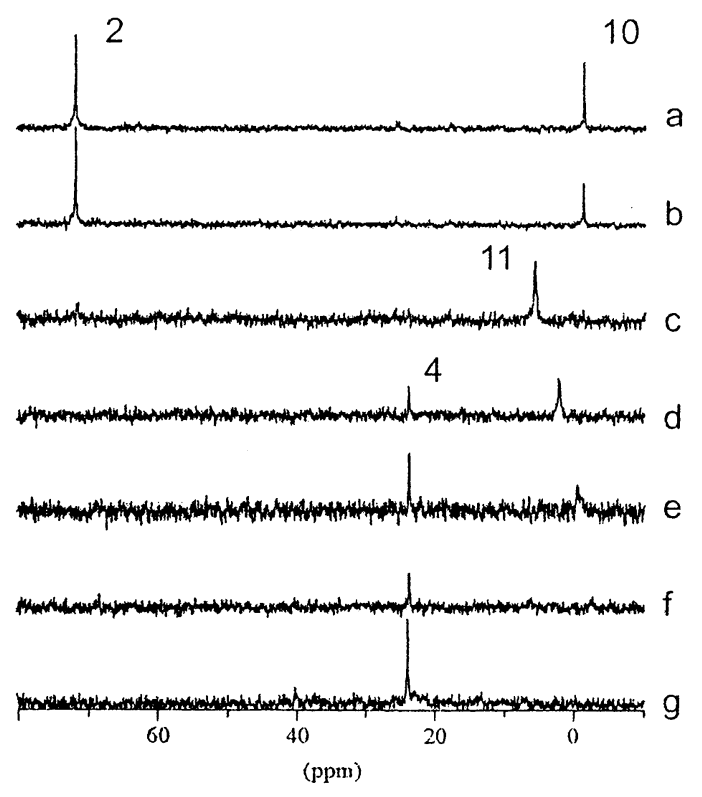

Figure 3. Variable-temperature ${ }^{31} \mathrm{P}\left\{{ }^{1} \mathrm{H}\right\} \quad N M R$ study (sapphire tube, $\mathrm{MeOH}-\mathrm{d}_{4}, 81.01 \mathrm{MHz}$ ) of the carbonylation reaction of ethene catalyzed by 2: (a) dissolving 2 in $\mathrm{MeOH}$ $\mathrm{d}_{4}$ under nitrogen at room temperature; (b) after the tube was pressurized with $40 \mathrm{bar}$ of $\mathrm{CO} / \mathrm{C}_{2} \mathrm{H}_{4}(1: 1)$ at room temperature; (c) at $40{ }^{\circ} \mathrm{C}$; (d) at $50{ }^{\circ} \mathrm{C}$; (e) at $60{ }^{\circ} \mathrm{C}$; (f) at $70{ }^{\circ} \mathrm{C}$; (g) after the tube was cooled to room temperature.

a new complex was formed (singlet at $\delta$ 23.7) featured by a quintet at $\delta-6.31(\mathrm{~J}(\mathrm{HP})=42.1 \mathrm{~Hz})$ in the ${ }^{1} \mathrm{H}$ NMR spectrum. On the basis of an independent synthesis, the new complex was identified as the $\mu$-hydrido, $\mu$-carbonyl complex $\left[\mathrm{Pd}_{2}(\mu-\mathrm{H})(\mu \text {-CO)(dppomf })_{2}\right] \mathrm{OTs}(\mathbf{4})$ (Chart 2). After $30 \mathrm{~min}$ at $70^{\circ} \mathrm{C}$, the probe-head was cooled to room temperature. The ${ }^{31} \mathrm{P}\left\{{ }^{1} \mathrm{H}\right\}$ NMR spectrum at this temperature showed that compound $\mathbf{4}$ was the only phosphorus-containing species visible in solution (trace g). Palladium metal in the tube indicated the occurrence of partial catalyst decomposition. ${ }^{1} \mathrm{H}$ NMR spectra acquired during the experiment showed that the formation of methyl propanoate- $\mathrm{d}_{4}$ (multiplets at $\delta 1.05$ and 2.27) had started at ca. $60{ }^{\circ} \mathrm{C}$.

In Situ High-Pressure NMR Study of the Methoxycarbonylation of Ethene Catalyzed by 2 in the Presence of $\mathbf{1 6}$ Equiv of BQ. A sequence of selected ${ }^{31} \mathrm{P}\left\{{ }^{1} \mathrm{H}\right\}$ NMR spectra is reported in Figure 4. A $10 \mathrm{~mm}$ sapphire HPNMR tube was charged under nitrogen with a solution of $\mathbf{2}$ in $\mathrm{MeOH}-\mathrm{d}_{4}$ and then placed into the NMR probe at room temperature.

As in the previous experiment, the first spectrum (trace a) showed the presence of both $\mathbf{2}$ and $\mathbf{1 0}$ in a ca. 5:1 ratio. Adding BQ (16 equiv) led to the immediate oxidative conversion of $\mathbf{1 0}$ into $\mathbf{2}$ (trace b). Pressurizing with a 1:1 mixture of $\mathrm{CO} / \mathrm{C}_{2} \mathrm{H}_{4}$ to 40 bar at room temperature caused the complete transformation of $\mathbf{2}$ into a new complex featured by a ${ }^{31} \mathrm{P}\left\{{ }^{1} \mathrm{H}\right\}$ NMR resonance at $\delta-19.1$ (trace c). On the basis of an in situ NMR characterization in methanol (see below) this complex was assigned the $\eta^{1}$-carbomethoxy complex [Pd$\left.\left(\mathrm{C}(\mathrm{O}) \mathrm{OCD}_{3}\right)(\mathrm{dppomf})\right] \mathrm{OTs}(\mathbf{1 2})$, where the metal center is coordinated in a square-planar environment by two trans phosphorus atoms from dppomf, a carbomethoxy group, and a dative $\mathrm{Fe}-\mathrm{Pd}$ bond (Chart 2). ${ }^{1,3 a, c, k}$ Increasing the temperature to $40^{\circ} \mathrm{C}$ caused the consumption of BQ (eq 1) with concomitant transformation of

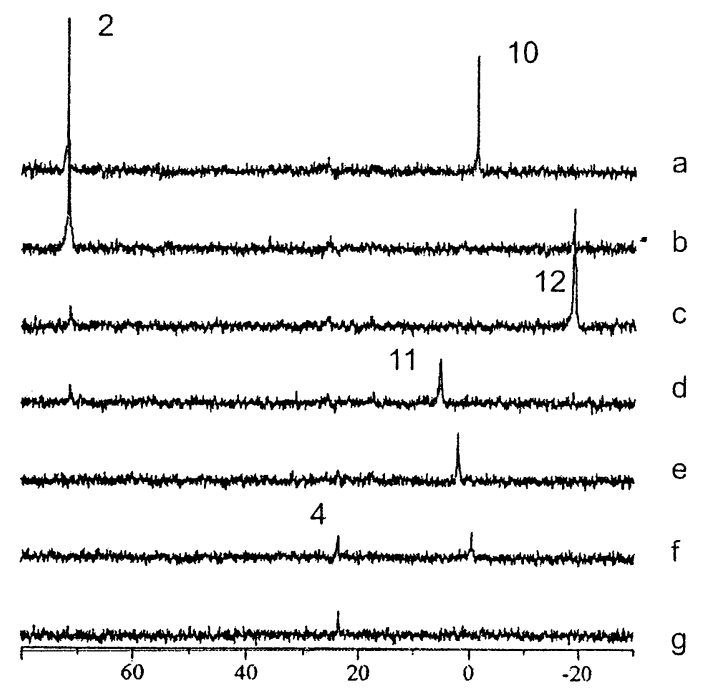

Figure 4. Variable-temperature ${ }^{31} \mathrm{P}\left\{{ }^{1} \mathrm{H}\right\}$ NMR study (sapphire tube, $\mathrm{MeOH}-\mathrm{d}_{4}, 81.01 \mathrm{MHz}$ ) of the carbonylation reaction of ethene catalyzed by 2: (a) dissolving 2 in $\mathrm{MeOH}$ $\mathrm{d}_{4}$ under nitrogen at room temperature; (b) after the addition of 16 equiv of $\mathrm{BQ}$; (c) after the tube was pressurized with 40 bar of $\mathrm{CO} / \mathrm{C}_{2} \mathrm{H}_{4}(1: 1)$ at room temperature; (d) at $40{ }^{\circ} \mathrm{C}$; (e) at $50^{\circ} \mathrm{C}$; (f) at $60^{\circ} \mathrm{C}$; (g) at $70^{\circ} \mathrm{C}$.

$\mathbf{1 2}$ into the $\mu$-CO dimer $\mathbf{1 1}$ (trace d). Upon a further increase of the temperature to $70{ }^{\circ} \mathrm{C}, \mathbf{1 1}$ converted to the $\mu$-hydride, $\mu$-CO complex 4 (traces $\mathrm{e}-\mathrm{g}$ ), while methyl propanoate began to form. After $30 \mathrm{~min}$ at 70 ${ }^{\circ} \mathrm{C}$, the tube was allowed to cool to room temperature. The ${ }^{31} \mathrm{P}\left\{{ }^{1} \mathrm{H}\right\}$ NMR spectrum at this temperature showed exclusively 4, yet traces of black palladium metal proved the occurrence of some catalyst degradation. ${ }^{1} \mathrm{H}$ NMR and GC/MS analyses confirmed the formation of methyl propanoate- $\mathrm{d}_{4}$.

In Situ High-Pressure NMR Study of the Methoxycarbonylation of Ethene Catalyzed by 2 in the Presence of 4 Equiv of TsOH. A $10 \mathrm{~mm}$ sapphire HPNMR tube was charged with a solution of $\mathbf{2}$ in $\mathrm{MeOH}-\mathrm{d}_{4}$ under nitrogen. The first spectrum at room temperature showed the presence of both $\mathbf{2}$ and $\mathbf{1 0}$ in a ca. 5:1 ratio. Upon addition of $\mathrm{TsOH}$ (4 equiv), 10 converted immediately to $\mathbf{2}$ completely. Pressurizing with a 1:1 mixture of $\mathrm{CO} / \mathrm{C}_{2} \mathrm{H}_{4}$ to 40 bar at room temperature caused the quantitative formation of the $\mu$-hydride, $\mu$-CO complex 4, which was also the only phosphorus-containing complex visible on the NMR time scal e during the carbonylation reaction $\left(1 \mathrm{~h}, 50-70^{\circ} \mathrm{C}\right)$. After $30 \mathrm{~min}$ at $70^{\circ} \mathrm{C}$, the probe-head was cooled to room temperature. The ${ }^{31} \mathrm{P}\left\{{ }^{1} \mathrm{H}\right\}$ NMR spectrum at this temperature showed only $\mathbf{4}$, while ${ }^{1} \mathrm{H}$ NMR and GC/MS analyses revealed the formation of methyl propanoate$\mathrm{d}_{4}$.

In Situ High-Pressure NMR Study of the Methoxycarbonylation of Ethene Catalyzed by 2 in the Presence of 4 Equiv of TsOH and 16 Equiv of BQ. A $10 \mathrm{~mm}$ sapphire HPNMR tube was charged under nitrogen with a solution of $\mathbf{2}, \mathrm{TsOH}$ (4 equiv), and $\mathrm{BQ}$ (16 equiv) in $\mathrm{MeOH}-\mathrm{d}_{4}(2 \mathrm{~mL})$ and then placed into the NMR probe at room temperature. The first spectrum showed only 2. Pressurizing to 40 bar with a 1:1 mixture of $\mathrm{CO} / \mathrm{C}_{2} \mathrm{H}_{4}$ at room temperature caused no change in both the ${ }^{1} \mathrm{H}$ and ${ }^{31} \mathrm{P}\left\{{ }^{1} \mathrm{H}\right\}$ NMR spectra. However, increasing the temperature to $50{ }^{\circ} \mathrm{C}$ decreased the 


\section{Scheme 7}

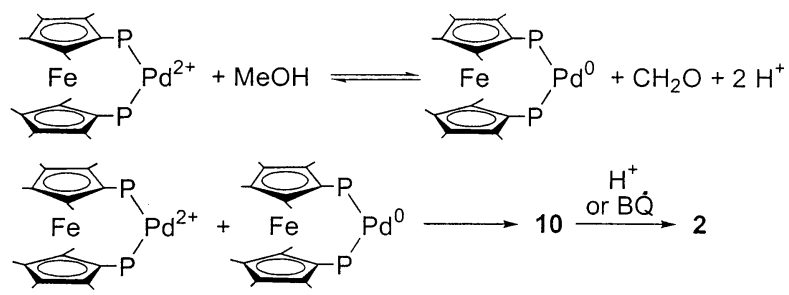

concentration of $\mathbf{2}$ and gave both $\mathbf{1 1}$ and $\mathbf{4}$, albeit in small amounts. At $60{ }^{\circ} \mathrm{C}$, only $\mathbf{1 1}$ and $\mathbf{4}$ were visible, with a higher concentration of the former complex. With time, the signal of $\mathbf{1 1}$ decreased in intensity. At $70^{\circ} \mathrm{C}$, 4 was the only visible phosphorus-containing species during the carbonylation reaction. After $30 \mathrm{~min}$ at 70 ${ }^{\circ} \mathrm{C}$, the probe-head was cool ed to room temperature. The ${ }^{31} \mathrm{P}\left\{{ }^{1} \mathrm{H}\right\} N \mathrm{NMR}$ spectrum at this temperature showed the exclusive presence of $\mathbf{4}$. As usual, palladium metal deposited on the bottom of the NMR tube. ${ }^{1} \mathrm{H}$ NMR and GC/MS analyses showed the formation of methyl propanoate-d 4 .

Synthesis and Characterization of Intermediates and Termination Products of the Methoxycarbonylation of Ethene by $\mathbf{2}$. Complex $\mathbf{1 0}$ was obtained by simply dissolving $\mathbf{2}$ in methanol. After 5 min, ca. 14\% 2 converted to 10, while the col or of the solution turned from green to brownish red. An in situ experiment monitored by NMR spectroscopy showed that both $\mathbf{2}$ and $\mathbf{1 0}$ were intrinsically unstable in methanol under $\mathrm{N}_{2}$, where they decomposed with time to unknown species, under release of protons. During this decomposition, the $\mathbf{2 / 1 0}$ ratio remained constant. All our attempts to isolate a sample of $\mathbf{1 0}$ by fractional crystallization were unsuccessful. Likewise, we were unable to develop an independent synthetic procedure to this $\mathrm{Pd}^{\mathrm{l}}-\mathrm{Pd} \mathrm{d}^{\mathrm{d}}$ dimer. Therefore, $\mathbf{1 0}$ was characterized by ${ }^{1} \mathrm{H}$ and ${ }^{31} \mathrm{P}\left\{{ }^{1} \mathrm{H}\right\}$ NMR spectroscopy in situ. Two magnetically equivalent phosphorus atoms and two largely separated signals for the methyl hydrogen atoms of the Cp* rings $(\Delta \delta=1.35)$ are strongly diagnostic for a structure in which the phosphorus atoms are trans to each other, and iron forms a dative bond to palladium using its $e_{2 g}$ el ectron density. ${ }^{3 a, c, k}$ Recent studies have demonstrated that the formation of dative iron-palladi um bonds in dppf and dppomf pal ladium complexes causes a tilting of the $C p$ rings. As a consequence of this tilting, the ${ }^{1} \mathrm{H}$ NMR $\Delta \delta$ of the $\alpha$ - and $\beta$-hydrogen atoms ( $\mathrm{H}$ in $\mathrm{Cp}, \mathrm{Me}$ in $\mathrm{Cp} \mathrm{p}^{*}$ ) is larger than that in the free ligand. ${ }^{3 a, c, k}$

Indirect support for the proposed structure for $\mathbf{1 0}$ was provided by its reactivity toward protic acids and oxidants. Indeed, treatment of methanol solutions of $\mathbf{1 0}$ with either $\mathrm{TsOH}$ or $\mathrm{BQ}$ regenerated $\mathbf{2}$ cleanly.

The dissol ution of mononucl ear ( $\mathrm{P}-\mathrm{P}) \mathrm{Pd}$ "l $^{\prime \prime}$ complexes in $\mathrm{MeOH}$ ( $\mathrm{P}-\mathrm{P}=$ chelating diphosphine) is a known procedure to prepare binuclear $\mathrm{Pd}^{\prime}$ complexes structurally similar to $10 \cdot 11,25,26$ The formation of these $\mathrm{Pd}^{\prime}-\mathrm{Pd}^{\prime}$ compounds has been proposed to involve the coupling of $(\mathrm{P}-\mathrm{P}) \mathrm{Pd}^{\prime \prime}$ and $(\mathrm{P}-\mathrm{P}) \mathrm{Pd}^{0}$ moieties, the latter being generated by palladium-promoted methanol oxidation to formaldehyde. ${ }^{9,25}$ Scheme 7 illustrates this process for 10.

The protons formed during the oxidation of methanol, converting $\mathbf{1 0}$ into $\mathbf{2}$, are likely to be responsible for the

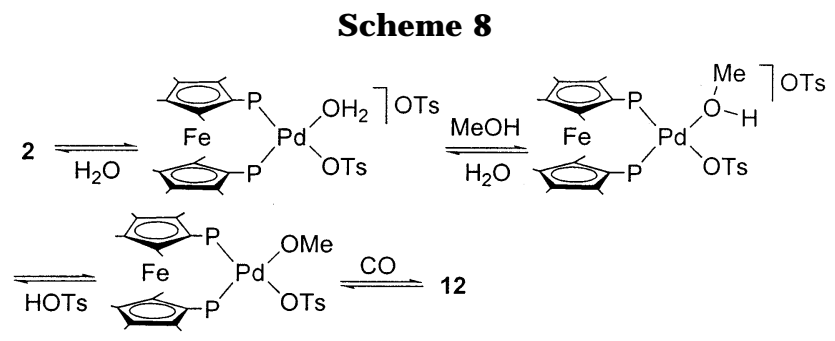

constant $\mathbf{2 / 1 0}$ ratio observed in the stability experiment described above.

Like 10, the $\mu$-CO binuclear complex $\mathbf{1 1}$ was neither isolated nor prepared through an independent procedure. All our efforts to prepare $\mathbf{1 1}$ led to the formation of either unidentified species or well-defined (dppomf)$\mathrm{Pd}^{0}$ complexes, such as $\left[\mathrm{Pd}(\mathrm{dppomf})_{2}\right]$ and the bis(carbonyl) complex $\left[\mathrm{Pd}(\mathrm{CO})_{2}(\mathrm{dppomf})\right],{ }^{28}$ none of which showing the spectral characteristics of $\mathbf{1 1}$. Indirect support for the proposed structure of $\mathbf{1 1}$ was provided by the following experiment: a $10 \mathrm{~mm}$ sapphire HPNMR tube was charged under nitrogen with a solution of 2 in $\mathrm{MeOH}-\mathrm{d}_{4}$ and pressurized to 40 bar with 1:1 CO/ $\mathrm{C}_{2} \mathrm{H}_{4}$ at room temperature. The tube was introduced into a spectrometer and heated to $40^{\circ} \mathrm{C}$. Already the first spectrum at this temperature showed the quantitative formation of $\mathbf{1 1}$ (see Figure 3, trace c). The tube was then removed from the probe head, frozen in liquid nitrogen, and subjected to vacuum to remove the gaseous phase. One equivalent of $\mathrm{TsOH}$ was added to the frozen solution. The tube was allowed to reach room temperature, where the quantitative formation of the $\mu$-hydride, $\mu$-CO complex 4 was observed by NMR spectroscopy.

Complex $\mathbf{4}$ was synthesized by the procedure described above for the dppf derivative $\mathbf{6}$, namely, the reaction of the aquo complex 2 with $\mathrm{CO}$ in $\mathrm{CH}_{2} \mathrm{Cl}_{2}$. Alternatively, 4 was prepared by pressurizing a mixture of 2 and TsOH (4 equiv) in methanol with $1: 1 \mathrm{CO} / \mathrm{C}_{2} \mathrm{H}_{4}$ in a HPNMR tube. Under these conditions, $\mathbf{4}$ can form according to the reaction sequence proposed in Scheme 5 for the dppf analogue 6, i.e., partial disproportionation of the $\mathrm{Pd}^{\prime \prime}$ system [PdH(dppomf)] $]^{+}$in the presence of $\mathrm{CO}$ to give $\mathrm{H}^{+}$and $[\mathrm{Pd}(\mathrm{CO})(\mathrm{dppomf})]$, followed by combination of the latter $\mathrm{Pd}^{0}$ fragment with residual $[\mathrm{PdH} \text { (dppomf) }]^{+}$.

Like $\mathbf{6}$ and other $\mu$-hydrido, $\mu$-carbonyl binuclear Pd complexes with chelating diphosphines, $\mathbf{4}$ is fluxional on the NMR time scale: the hydride resonance in the ${ }^{1} \mathrm{H}$ NMR spectrum appears as a quintet with $\delta-6.02$ $(\mathrm{J}(\mathrm{HP})=42.6 \mathrm{~Hz})$ at $20^{\circ} \mathrm{C}$ and as a triplet of triplets with $\delta-5.72\left({ }^{2} \mathrm{~J}(\mathrm{HP})=80.8,5.2 \mathrm{~Hz}\right)$ at $-70{ }^{\circ} \mathrm{C} .{ }^{8,12}$

Pressurizing a methanol solution of $\mathbf{2}$ with $\mathrm{CO}$ gave the carbomethoxy complex $\mathbf{1 2}$ quantitatively, likely through CO insertion into a $\mathrm{Pd}^{\prime \prime}$ methoxy intermediate that was not intercepted (Scheme 8).2,29

A carbon resonance at 209.9 in the ${ }^{13} \mathrm{C}\left\{{ }^{1} \mathrm{H}\right\}$ NMR spectrum was diagnostic for the presence of a carbomethoxy group in 12, whilethelack of additional $\mathrm{P}-\mathrm{C}$ couplings in the ${ }^{31} \mathrm{P}\left\{{ }^{1} \mathrm{H}\right\}$ NMR spectrum, when ${ }^{13} \mathrm{CO}$ was used in the place of ${ }^{12} \mathrm{CO}$, was consistent with a trans arrangement of the phosphorus atoms. ${ }^{3 a, c, k} \mathrm{Fi}$ -

(28) Bianchini, C.; Meli, A.; Oberhauser, W., manuscript in preparation.

(29) Milstein, D. Acc. Chem. Res. 1988, 212, 428. 


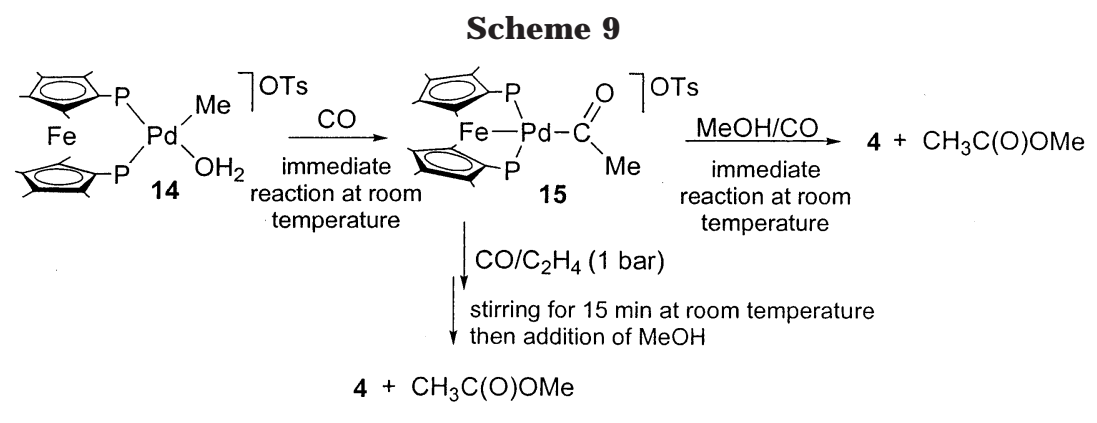

nally, a strong argument in favor of the $\eta^{3}-P, P, F e$ bonding mode of dppomf in $\mathbf{1 2}$ was provided by the large difference between the chemical shifts of the $\alpha$ and $\beta$ methyl hydrogen atoms of the Cp* rings $(\Delta \delta=0.87))^{3 a, c, k}$

Under CO atmosphere, $\mathbf{1 2}$ underwent methanolysis at room temperature very slowly ( $\mathrm{t}_{1 / 2} \mathrm{ca} .12 \mathrm{~h}$ ), yiel ding dimethyl carbonate (GC/MS analysis) and the (hydrido)carbonyl complex 4.

Some possible intermediates in Scheme 8 have been represented with arbitrary molecular structures. Our preference for a chelating $\eta^{2}-P, P$ dppomf ligand in these compounds stems from the nature of the co-ligands, which are neither sterically demanding nor electronwithdrawing ( $\mathrm{H}, \mathrm{OMe}, \mathrm{OTs})$. Indeed, both characteristics disfavor the formation of a dative $\mathrm{Fe}-\mathrm{Pd}$, which requires either bulky or electron-withdrawing coligands. ${ }^{3 a, c}$

Model Study of the Methoxycarbonylation of Ethene by Pd ${ }^{\prime \prime}$-dppomf Catalysis. The methyl complex $\left[\mathrm{Pd}(\mathrm{Me})\left(\mathrm{H}_{2} \mathrm{O}\right)(\mathrm{dppomf})\right] \mathrm{OTs}(\mathbf{1 4})$ was straightforwardly prepared by reaction of [PdCl(Me)(dppomf)] (13) with AgOTs in $\mathrm{CH}_{2} \mathrm{Cl}_{2}$ solution. In the presence of $1 \mathrm{bar}$ of $\mathrm{CO}$ at room temperature, $\mathbf{1 4}$ converted immediately into the acyl complex [Pd(COMe)(dppomf)]OTs (15) (Scheme 9). The different hapticity of dppomf in $\mathbf{1 4}$ and 15 was unequivocally put in evidence by the corresponding ${ }^{31} \mathrm{P}\left\{{ }^{1} \mathrm{H}\right\}$ NMR patterns: AM system with $\delta$ $48.8(\mathrm{br})$ and 12.6 ( $\mathrm{J}(\mathrm{PP})=20.5 \mathrm{~Hz}$ ), and $\mathrm{A}_{2}$ system with $\delta-13.3$, respectively. The ${ }^{1} \mathrm{H}$ NMR resonances of the Cp* methyl groups were in line with the different hapticity of dppomf in the two compounds, showing four close signals for $\mathbf{1 4}$ and two well-separated signals for 15.

The acyl complex 15 in $\mathrm{CD}_{2} \mathrm{Cl}_{2}$ underwent fast methanolysis at room temperature, yielding the $\mu$-hydride, $\mu$-CO complex 4 (see Scheme 5) and methyl acetate (Scheme 9). Complex $\mathbf{4}$ and methyl acetate were selectively produced also when $\mathrm{MeOH}$ was added to a $\mathrm{CD}_{2} \mathrm{Cl}_{2}$ solution of $\mathbf{1 5}$ previously saturated with a 1:1 $\mathrm{CO} / \mathrm{C}_{2} \mathrm{H}_{4}$ mixture at room temperature. It is worth noticing that the carbomethoxy complex 12, containing a dative $\mathrm{Fe}-\mathrm{Pd}$ bond like $\mathbf{1 5}$, undergoes al coholysis very slowly even in neat $\mathrm{MeOH}$ (vide infra), which reflects the lower electrophilic character of the $\mathrm{CO}_{2} \mathrm{R}$ carbon atom as compared to the COR carbon atom.

\section{Discussion}

The overall mechanism accounting for the nature of the oxygenated products obtained by methoxycarbonylation of ethene with $\mathbf{1}$ and $\mathbf{2}$ (Scheme 1) has been reported previously. ${ }^{1}$ The results of the present study highlight mechanistic details regarding the propagation and termination steps of the alternating copolymeriza- tion catalyzed by $\mathbf{1}$ as well as rationalize the different selectivity of the dppf and dppomf catalysts.

Scheme 10 shows mechanistic details for the reactions assisted by the dppf-modified catalyst.

On the basis of the experimental results and model studies described in the section above, one may conclude that the behavior of the dppf precursor 1 in the methoxycarbonylation of ethene is quite similar to that of any other Pd"l catalyst modified with a chelating diphosphine. ${ }^{2}$ In particular, the formation of $\beta$-chelate intermediates from either $\mathrm{Pd}-\mathrm{H}$ or $\mathrm{Pd}-\mathrm{OMe}$ has been experimentally determined (Figure 1 ), and their importance in controlling the perfect alternation of monomers has been demonstrated in the model studies illustrated in Schemes 2 and 3.

The formation of the $\mu$-OH binuclear complex $\mathbf{3}$ during the catalysis together with that of diethyl ketone demonstrate that the chain transfer can proceed by protonolysis of Pd-alkyl, most likely through the enolate mechanism reported by van Leeuwen et al. (Scheme 6). ${ }^{3 f}$ The chain transfer by protonolysis seems to be much less important than that by methanolysis of Pd-acyl, however. In fact, the production of diethyl ketone occurred in very low yield and only in the presence of an excess of protic acid. U pon methanolysis of Pd-acyl, the $\mathrm{Pd}-\mathrm{H}$ moiety is regenerated, which can initiate the next catalytic cycle; however, this species is unstable and can also degrade to the hydride(carbonyl) complex 6 through the mechanism reported in Scheme 5. The termination product $\mathbf{3}$ is not a dead-end for the catalytic reaction, as it may be considered a resting state for catalytically active $\mathrm{Pd}^{\prime \prime}$ (Table 1 , entries $10-13$ ). The mechanism by which $[\mathrm{Pd}(\mu-\mathrm{OH})(\mathrm{P}-\mathrm{P})]_{2}{ }^{2+}$ complexes may re-enter the copolymerization cycle has been proposed to involve the cl eavage of the bi nuclear structure by $\mathrm{CO}$, followed by a water-gas-shift process to generate $\mathrm{Pd}-\mathrm{H}$ moieties. ${ }^{5 c, 7}$

In contrast to $\mathbf{1}$, the dppomf precursor $\mathbf{2}$ yields methyl propanoate exclusively, irrespective of the experimental conditions (Table 1), which means that the whole activity of the dppomf-modified catalyst is confined in the reaction sequence reported in Scheme 11. Indeed, the al ternative path to generate methyl propanoate via protonolysis of a possible $\beta$-chelate complex of the formula $\left[\mathrm{Pd}\left(\mathrm{CH}_{2} \mathrm{CH}_{2} \mathrm{C}(\mathrm{O}) \mathrm{OMe}\right)(\mathrm{dppomf})\right]^{+}$can be ruled out on the basis of both direct evidence and model studies.

The HPNMR studies did not reveal the formation of any $\beta$-chelate species with dppomf at any stage of the carbonylation reaction under a $\mathrm{CO} / \mathrm{C}_{2} \mathrm{H}_{4}$ pressure of 40 bar, while methyl propanoate was selectively and efficiently produced under conditions that do not allow for the formation of $\mathrm{Pd}-\mathrm{C}(\mathrm{O}) \mathrm{OMe}$ initiators (i.e., in the 


\section{Scheme 10}

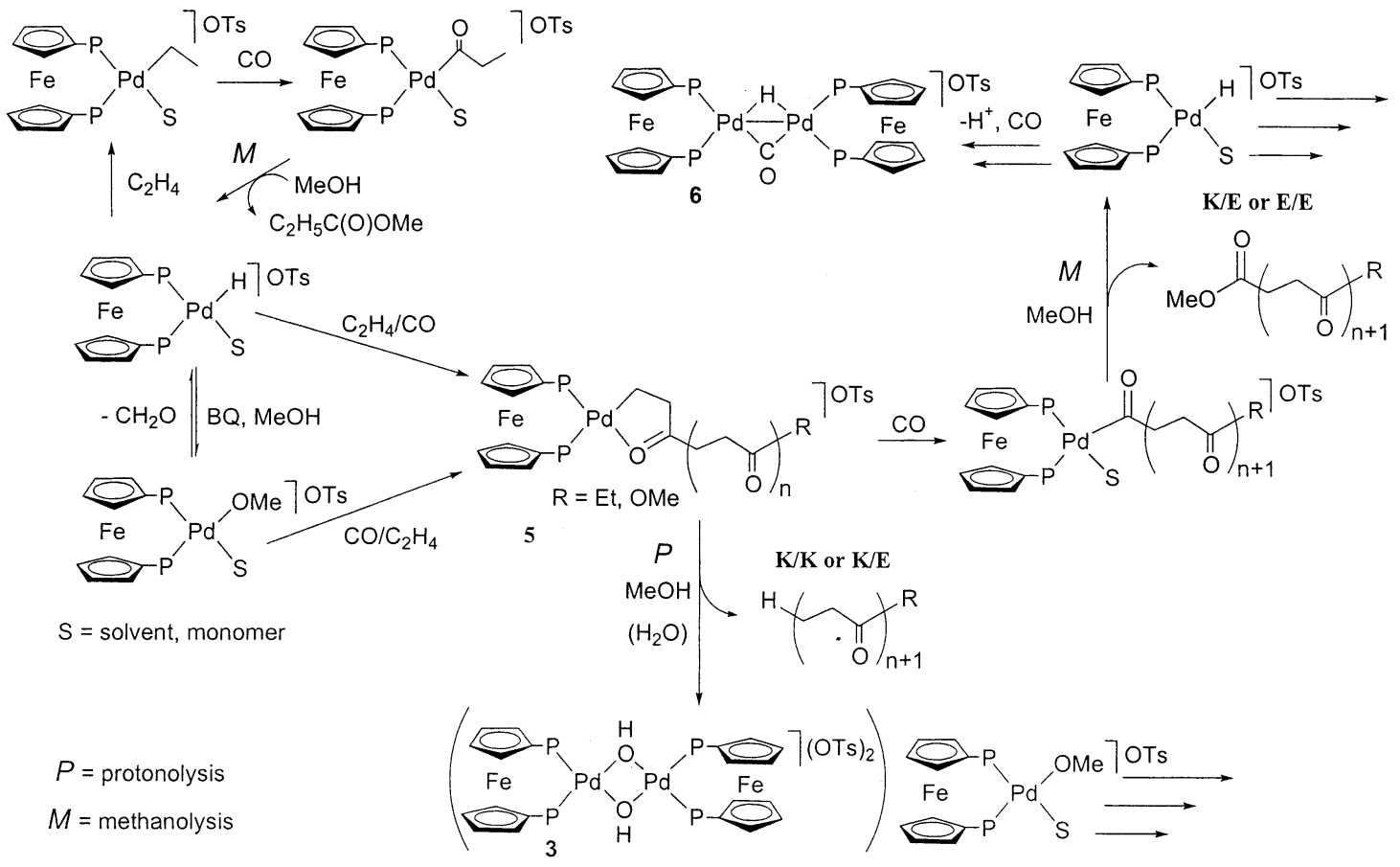

\section{Scheme 11}

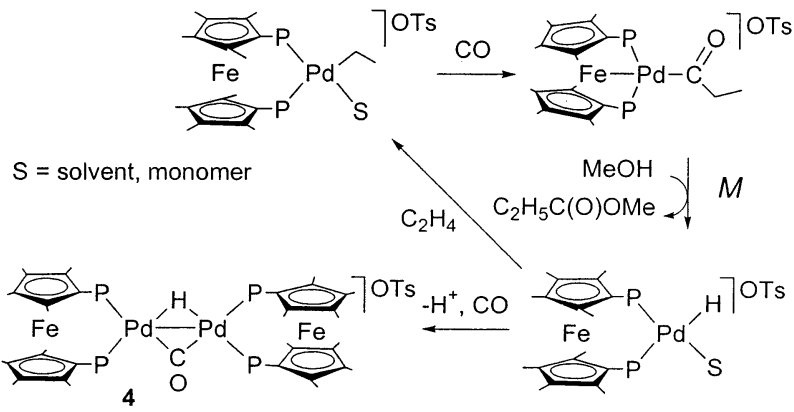

presence of a large excess of acid, see Table 1, entry 18). The occurrence of the Pd-OMe mechanism is unlikely on the basis of the results of the model study with the acyl complex $\mathbf{1 5}$ that showed the methanolysis of $\mathbf{1 5}$, yiel ding methyl acetate and $\mathbf{4}$, to be much faster than the insertion of ethene into Pd-COMe to give a Pd-alkyl (Scheme 9). Studies underway in this laboratory confirm that the insertion of ethene into the $\mathrm{Pd}-\mathrm{COMe}$ bond of 15 is a thermodynamically allowed process in $\mathrm{CH}_{2} \mathrm{Cl}_{2}$, yet kinetically disfavored over alcoholysis by $\mathrm{MeOH}$ even under a high pressure of ethene (20 bar). ${ }^{28}$ In this respect, the behavior of the $\eta^{3}-P, P, F e d p p o m f$ acyl complex 15 contrasts dramatically with that of the $\eta^{2}$ P,P-dppf analogues [Pd(COR)(S)(dppf) $]^{+}(\mathrm{S}=\mathrm{MeOH}$, monomer), which convert to $\beta$-chelate species by reaction with $\mathrm{C}_{2} \mathrm{H}_{4}$ even in neat $\mathrm{MeOH}$ (Figure 1). ${ }^{12,30}$

The $\mathrm{Pd}-\mathrm{H}$ initiator in Scheme 11 has been drawn as containing an $\eta^{2}$-chelating dppomf ligand. Although this representation is arbitrary, as no spectroscopic evidence whatsoever was obtained for a mononuclear $\mathrm{Pd}-\mathrm{H}$ complex during the catalysis, the probability that such an intermediate contains a $\eta^{2}$-P,P-dppomf ligand is indeed very high. The hydride ligand lacks all important

(30) van Leeuwen, P. W. N. M.; Zuideveld, M. A.; Swennenhuis, B. H. G.; Freixa, Z.; Kamer, P. C. J .; Goubitz, K.; Fraanje, J .; Lutz, M.; Spek, A. L., submitted for publication. criteria, established in the course of previous studies, $3 a, c, k$ for the formation of a dative $\mathrm{Fe}-\mathrm{Pd}$ bond in [PdL(ferrocenyldiphosphine) ${ }^{+}$complexes; that is, L must be bulky or have an electron-withdrawing character to make the Pd center susceptible to accept $e_{2 g}$ electron density from iron. Consistent with this rule, the methyl derivative $\mathbf{1 4}$ exhibits a chel ating dppomf ligand, while the acyl complex $\mathbf{1 5}$ contains a dative $\mathrm{Fe}-\mathrm{Pd}$ bond and trans $\mathrm{P}$ atoms.

The overall TOFs obtained with $\mathbf{2}$ are by far lower than those obtained with $\mathbf{1}$ under comparable conditions (Table 1). The propensity of the precursor $\mathbf{2}$ to degrade spontaneously to the $\mathrm{Pd}^{\prime}-\mathrm{Pd}^{\prime}$ binuclear complex $\mathbf{1 0}$ and, under $\mathrm{CO} / \mathrm{C}_{2} \mathrm{H}_{4}$, to the $\mathrm{Pd}^{0} \mu$-CO complex $\mathbf{1 1}$ may well account for the low productivity of the dppomf-modified catalyst. Another factor that can contribute to decrease the catalytic activity of $\mathbf{2}$ is the formation of a propionyl intermediate with a dative $\mathrm{Fe}-\mathrm{Pd}$ bond and trans $\mathrm{P}$ atoms (Scheme 11). In fact, the methanolysis of the propionyl intermediate may be rate limiting in the catalysis cycle shown in Scheme 11, as it involves the reaction of $\mathrm{MeOH}$ with a coordinatively saturated square-planar Pd"l complex. To accomplish this reaction, a change in the hapticity of dppomf from $\eta^{3}-\mathrm{P}, \mathrm{P}, \mathrm{Fe}$ (trans $\mathrm{P}$ atoms) to $\eta^{2}-\mathrm{P}, \mathrm{P}$ (cis $\mathrm{P}$ atoms) is required to provide a free coordination site for $\mathrm{MeOH}$ coordination and to allow for the nucleophilic attack by the oxygen atom to the acyl carbon atom. The energy barrier to this hapticity change is presumably high. Moreover, as recently shown by van Leeuwen et al., ${ }^{30}$ under acidic conditions methanol is a too weak a nucleophile to give direct attack from solution.

The stabilizing effect of the $\eta^{3}-\mathrm{P}, \mathrm{P}, \mathrm{F}$ edppomf bonding mode seems to be particularly important in the methoxycarbonylation reactions carried out in the presence of an excess of BQ, yielding a TOF of 95 only (Table 1 , entry 19). The organic oxidant, promoting the conversion of $\mathrm{Pd}-\mathrm{H}$ into $\mathrm{Pd}-\mathrm{C}(\mathrm{O}) \mathrm{OMe}$ (eq 1 ), increases the concentration of the $\eta^{3}-\mathrm{P}, \mathrm{P}, \mathrm{Fe}$ edppomf carbomethoxy 
complex 12 (Figure 4), which is not a good catalyst precursor to form Pd-H due to its reluctance to undergo methanolysis.

\section{Conclusions}

The square-planar palladium(II) complexes $\left[\mathrm{Pd}\left(\mathrm{H}_{2} \mathrm{O}\right)_{2}\right.$ (dppf)](OTf $)_{2}$ and $\left[\mathrm{Pd}\left(\mathrm{H}_{2} \mathrm{O}\right)_{2}(\mathrm{dppomf})\right](\mathrm{OTf})_{2}$ are effective catalysts for the methoxycarbonylation of ethene, yet they exhibit quite different selectivity: the dppf-modified catalyst produces several low molecular weight oxygenates, spanning from methyl propanoate to alternating oligoketones, while the dppomf catalyst yields exclusively methyl propanoate. Batch catalytic reactions, in situ high-pressure NMR experiments, and model studies with isolated compounds agree to indicate the greater propensity of dppomf versus dppf to form palladium(II) complexes with a dative $\mathrm{Fe}-\mathrm{Pd}$ bond as the factor leading to the selective production of methyl propanoate. In fact, the presence of an $\mathrm{Fe}-\mathrm{Pd}$ bond forces the $\mathrm{P}$ atoms to be trans to each other and ultimately results in Pd-acyl species that do not react with ethene in $\mathrm{MeOH}$.

\section{Experimental Section}

General Procedures. All reactions and manipulations were carried out under an atmosphere of nitrogen using Schlenk-type techniques. All reagents and solvents were used as purchased from commercial suppliers. The complexes $\mathrm{PdCl}$ (Me)(COD) (COD = cycloocta-1,5-diene), ${ }^{31}\left[\mathrm{Pd}\left(\mathrm{H}_{2} \mathrm{O}\right)_{2}(\mathrm{dppf})\right]-$ $(\mathrm{OTs})_{2},{ }^{1}\left[\mathrm{Pd}\left(\mathrm{H}_{2} \mathrm{O}\right)_{2}\right.$ (dppomf)](OTs) ${ }_{2},{ }^{1}[\mathrm{Pd}(u-\mathrm{OH})(\mathrm{dppf})]_{2}(\mathrm{OTs})_{2},{ }^{3 n}$ $[\mathrm{Pd}(\mathrm{Me})(\mathrm{NCMe})(\mathrm{dppf})] \mathrm{OTf},{ }^{31}$ and [Pd(COMe)(NCMe)(dppf)]OTs $s^{31}$ were synthesized according to published procedures. All the isol ated solid samples were collected on sintered-glass frits and washed with appropriate solvents before being dried under a stream of nitrogen. Elemental analyses were performed using a Carlo Erba Model 1106 elemental analyzer. Infrared spectra were recorded on a Perkin-E Imer 1600 Series FT-IR spectrophotometer. Conductivities were measured with an ORION model 990101 conductance cell connected to a model 101 conductivity meter. The conductivity data ${ }^{32}$ were obtained at sample concentrations of ca. $10^{-3} \mathrm{M}$ in nitroethane solutions. Carbonylation reactions were performed with a $250 \mathrm{~mL}$ stainless steel autoclave, constructed at the ICCOM-CNR (Firenze, Italy), equipped with a magnetic drive stirrer and a Parr 4842 temperature and pressure controller. The autoclave was connected to a gas reservoir to maintain a constant pressure over all the catalytic reactions. Deuterated solvents for routine NMR measurements were dried over molecular sieves. ${ }^{1} \mathrm{H},{ }^{13} \mathrm{C}\left\{{ }^{1} \mathrm{H}\right\}$, and ${ }^{31} \mathrm{P}\left\{{ }^{1} \mathrm{H}\right\}$ NMR spectra were obtained a Bruker ACP 200 spectrometer (200.13, 50.32, and 81.01 $\mathrm{MHz}$, respectively). Chemical shifts are reported in ppm $(\delta)$ with reference to either TMS as an internal standard $\left({ }^{1} \mathrm{H}\right.$ and ${ }^{13} \mathrm{C}\left\{{ }^{1} \mathrm{H}\right\}$ NMR spectra) or $85 \% \mathrm{H}_{3} \mathrm{PO}_{4}$ as an external standard ( ${ }^{31} \mathrm{P}\left\{{ }^{1} \mathrm{H}\right\}$ NMR spectra). The $10 \mathrm{~mm}$ sapphire NMR tube was purchased from Saphikon, Milford, $\mathrm{NH}$, while the titanium high-pressure charging head was constructed at the ICCOMCNR (Firenze, Italy). ${ }^{33}$ Caution: Since high gas pressures are involved, safety precautions must be taken at all stages of studies involving high-pressure NMR tubes. GC analyses were performed on a Shimadzu GC-14 A gas chromatograph equipped with a flame ionization detector and a $30 \mathrm{~m}(0.25 \mathrm{~mm}$ i.d., 0.25 $\mu \mathrm{m}$ film thickness) SPB-1 Supel co fused silica capillary column.

(31) (a) Drew, D.; Doyle, J . R. I norg. Synth. 1972, 13, 52. (b) Rülke, R. E.; Ernsting, J . M.; Spek, A. L.; Elsevier, C. J .; van Leeuwen, P. W. N. M.; Vrieze, K. Inorg. Chem. 1993, 16, 9, 5972.

(32) (a) Geary, W. J . Coord. Chem. Rev. 1971, 7, 81. (b) Morassi, R.; Sacconi, L. J . Chem. Soc. A 1971, 492.
The product composition of the catalytic reactions was determined by using dimethyl oxalate as the internal standard. GC/ MS analyses were performed on a Shimadzu QP 5000 apparatus equipped with a column identical with that used for GC analysis.

Catalytic Carbonylation of Ethene in Methanol. Typically, $\mathrm{MeOH}(100 \mathrm{~mL})$ was introduced by suction into a 250 $\mathrm{mL}$ autoclave, previously evacuated by a vacuum pump, containing $0.01 \mathrm{mmol}$ of catalyst precursor along with the desired amounts of $\mathrm{BQ}$ and/or TsOH. The autoclave was then pressurized with $1: 1 \mathrm{CO} / \mathrm{C}_{2} \mathrm{H}_{4}(600 \mathrm{psi})$ at room temperature and heated to $85^{\circ} \mathrm{C}$. As soon as the reaction mixture in the autodave reached the desired temperature, stirring (1400 rpm) was applied for the desired time (1-3h). A constant pressure was maintained over all the experiments by a continuous feeding of the same mixture of $\mathrm{CO} / \mathrm{C}_{2} \mathrm{H}_{4}$ from a gas reservoir. The reaction was stopped by cooling the autoclave to room temperature by means of an ice bath. After the unreacted gases were released, the insoluble $\mathrm{CO} / \mathrm{C}_{2} \mathrm{H}_{4}$ material, if any, was filtered off, washed with cold $\mathrm{MeOH}$, and dried overnight under reduced pressure at $70^{\circ} \mathrm{C}$. The filtrate was analyzed by GC using dimethyl oxalate as the internal standard.

Characterization of the Co-oligomers. The elemental analysis values were in agreement with a $\mathrm{CO} / \mathrm{C}_{2} \mathrm{H}_{4}$ ratio of 1 . Spectroscopically (IR and NMR), the oligomers showed chemical-physical properties comparable to those reported in the literature for perfectly alternating copolymers obtained by $\mathrm{CO} /$ $\mathrm{C}_{2} \mathrm{H}_{4}$ copolymerization in methanol by $\mathrm{Pd}^{\mathrm{Il}}$-diphosphine catalysis. ${ }^{2}$ In general, all samples showed the presence of both ketonic and ester end groups; however, a different ratio of these groups was observed depending on the reaction conditions. Anal. Calcd for $\left(\mathrm{COCH}_{2} \mathrm{CH}_{2}\right)_{n}$ : C, 64.27; H, 7.19. Found: $\mathrm{C}, 64.21 ; \mathrm{H}, 7.16$. IR (powder sample in $\mathrm{KBr}$ pellet): 3391 (w), 2912 (m), 1694 (vs), 1408 (s), 1333 (s), 1259 (m), 1056 (s), $811(\mathrm{~m}), 592(\mathrm{~m}) \mathrm{cm}^{-1}$. ${ }^{1} \mathrm{H}$ NMR $\left(\mathrm{HFIP}-\mathrm{d}_{2}\right): \delta 3.73\left(\mathrm{~s}, \mathrm{CH}_{2-}\right.$ $\left.\mathrm{CO}_{2} \mathrm{CH}_{3}\right), 2.83\left(\mathrm{~s}, \mathrm{CH}_{2} \mathrm{COCH}_{2}\right), 2.55(\mathrm{q}, \mathrm{J}(\mathrm{HH})=7.4 \mathrm{~Hz}$, $\left.\mathrm{COCH}_{2} \mathrm{CH}_{3}\right), 1.09\left(\mathrm{t}, \mathrm{J}(\mathrm{HH})=7.4 \mathrm{~Hz}, \mathrm{COCH}_{2} \mathrm{CH}_{3}\right) \cdot{ }^{13} \mathrm{C}\left\{{ }^{1} \mathrm{H}\right\}$ NMR (HFIP/CDCl $, 9: 1, \mathrm{v} / \mathrm{v}): \delta 217.2\left(\mathrm{COCH}_{2} \mathrm{CH}_{3}\right), 213.0$ $\left(\mathrm{CH}_{2} \mathrm{COCH}_{2}\right), 176.6\left(\mathrm{CH}_{2} \mathrm{CO}_{2} \mathrm{CH}_{3}\right), 52.6\left(\mathrm{CH}_{2} \mathrm{CO}_{2} \mathrm{CH}_{3}\right), 36.1$ $\left(\mathrm{CH}_{2} \mathrm{COCH}_{2}\right), 27.9\left(\mathrm{CH}_{2} \mathrm{CO}_{2} \mathrm{CH}_{3}\right), 7.1\left(\mathrm{COCH}_{2} \mathrm{CH}_{3}\right)$.

In Situ HPNMR Study of the Methoxycarbonylation of Ethene Catalyzed by 1. A $10 \mathrm{~mm}$ sapphire HPNMR tube was charged under nitrogen with a solution of $\mathbf{1}(13.5 \mathrm{mg}$, $0.013 \mathrm{mmol})$ in $\mathrm{MeOH}-\mathrm{d}_{4}(2 \mathrm{~mL})$ and then pressurized with a 1:1 mixture of $\mathrm{CO} / \mathrm{C}_{2} \mathrm{H}_{4}$ to 40 bar at room temperature. The reaction was followed by variable-temperature ${ }^{31} \mathrm{P}\left\{{ }^{1} \mathrm{H}\right\}$ and ${ }^{1} \mathrm{H}$ NMR spectroscopy. A sequence of selected ${ }^{31}{ }^{1}\left\{{ }^{1} \mathrm{H}\right\} N M R$ spectra is reported in Figure 1. NMR data for 1: ${ }^{11} \mathrm{P}\left\{{ }^{1} \mathrm{H}\right\}$ NMR $\left(\mathrm{MeOH}-\mathrm{d}_{4}, 2{ }^{\circ} \mathrm{C}\right): \delta 47.9(\mathrm{~s}) .{ }^{1} \mathrm{H} \mathrm{NMR}\left(\mathrm{MeOH}-\mathrm{d}_{4}, 2{ }^{\circ} \mathrm{C}\right): \delta$ 8.0-7.0 (m, 28H, Ar-PPh + Ar-OTs), 4.69 (s, 4H, H-Cp), 4.55 (s, 4H, H-Cp), 2.23 (s, 6H, Me-OTs).

Synthesis of 6. A. A solution of $1(130 \mathrm{mg}, 0.13 \mathrm{mmol})$ in $\mathrm{CH}_{2} \mathrm{Cl}_{2}(20 \mathrm{~mL})$ was introduced into a $100 \mathrm{~mL}$ autoclave and pressurized with $\mathrm{CO}$ to 20 bar at room temperature. After 2 $\mathrm{h}$, the unreacted gas was released and the contents were transferred into a round-bottomed flask and concentrated to half the volume under vacuum. The solution was filtered on Celite to eliminate precipitated palladium, and a 3:1 mixture of $\mathrm{n}$-hexane/diethyl ether $(10 \mathrm{~mL})$ was added to preci pitate 6 , which was collected on a sintered-glass frit, washed with n-hexane, and dried under a stream of nitrogen. Yield: $70 \%$. Anal. Calcd for $\mathrm{C}_{76} \mathrm{H}_{64} \mathrm{Fe}_{2} \mathrm{O}_{4} \mathrm{P}_{4} \mathrm{Pd}_{2} \mathrm{~S}$ : C, 59.98; $\mathrm{H}, 4.24$. Found: C, 59.89; $\mathrm{H}, 4.22 .{ }^{31} \mathrm{P}\left\{{ }^{1} \mathrm{H}\right\} N M R\left(20^{\circ} \mathrm{C}\right): \delta\left(\mathrm{MeOH}-\mathrm{d}_{4}\right) 19.6(\mathrm{br}$ s); $\left(\mathrm{CD}_{2} \mathrm{Cl}_{2}\right): 18.5$ (br s). ${ }^{31 P} \mathrm{NMR}\left(\mathrm{CD}_{2} \mathrm{Cl}_{2}, 20^{\circ} \mathrm{C}\right): \delta 18.5(\mathrm{~d}$, 2) $(\mathrm{PH})=42.1 \mathrm{~Hz}) .{ }^{1} \mathrm{H}$ NMR $\left(20{ }^{\circ} \mathrm{C}\right): \delta\left(\mathrm{CD}_{2} \mathrm{Cl}_{2}\right) 8.0-6.9(\mathrm{~m}$, $\left.44 \mathrm{H}, \mathrm{Ar}-\mathrm{PPh}_{2}+\mathrm{Ar}-\mathrm{OTs}\right), 4.38$ (s, 8H, H-Cp), 4.11 (s, 8H, H-Cp), $2.32(\mathrm{~s}, 3 \mathrm{H}, \mathrm{Me}-\mathrm{OTs}),-6.08$ (quintet, ${ }^{2} \mathrm{~J}(\mathrm{HP})=41.9 \mathrm{~Hz}, 1 \mathrm{H}$, $\mu-\mathrm{H}) ;\left(\mathrm{MeOH}-\mathrm{d}_{4}\right)$ 8.0-7.0 (m, 44H, $\left.\mathrm{Ar}^{-\mathrm{PPh}_{2}}+\mathrm{Ar}-\mathrm{OTs}\right), 4.69$ (s, 8H, H-Cp), 4.54 (s, 8H, H-Cp), 2.23 (s, 3H, Me-OTs), -6.01 (quintet, $\left.{ }^{2} \mathrm{~J}(\mathrm{HP})=42.0 \mathrm{~Hz}, 1 \mathrm{H}, \mu-\mathrm{H}\right) .{ }^{13} \mathrm{C}\left\{{ }^{1} \mathrm{H}\right\} \mathrm{NMR}\left(\mathrm{CD}_{2} \mathrm{Cl}_{2}\right.$, 
$20{ }^{\circ} \mathrm{C}$ ): $\delta 229.7$ (quintet, ${ }^{2} \mathrm{~J}(\mathrm{CP})=34.1 \mathrm{~Hz}, \mu$-CO). IR $\left(\mathrm{CH}_{2-}\right.$ $\left.\mathrm{Cl}_{2}, \mathrm{~cm}^{-1}\right): 1841$ (CO).

B. Methanol (10 equiv) was syringed into a $5 \mathrm{~mm} \mathrm{NMR}$ tube containing a $3.3 \times 10^{-2} \mathrm{M}$ solution of $[\mathrm{Pd}(\mathrm{COM})(\mathrm{NCM} \mathrm{e})(\mathrm{dppf})]$ OTs in $\mathrm{CD}_{2} \mathrm{Cl}_{2}(0.7 \mathrm{~mL})$ under 1 bar of $\mathrm{CO}$ at room temperature. ${ }^{1} \mathrm{H}$ and ${ }^{31} \mathrm{P}\left\{{ }^{1} \mathrm{H}\right\}$ NMR spectra showed the quantitative formation of the dimer $5\left({ }^{31} \mathrm{P}\left\{{ }^{1} \mathrm{H}\right\} \mathrm{NMR}\right.$ singlet at $\delta 18.5 ;{ }^{1} \mathrm{H}$ quintet for the hydride at $-6.08(2 \mathrm{~J}(\mathrm{HP})=41.9 \mathrm{H})$ ) and methyl acetate. ${ }^{12}$ The use of ${ }^{13} \mathrm{CO}$ resulted in an additional $\mathrm{P}-\mathrm{C}$ coupling in the ${ }^{31} \mathrm{P}\left\{{ }^{1} \mathrm{H}\right\}$ NMR spectrum $\left(\mathrm{d},{ }^{2} \mathrm{~J}(\mathrm{PC})=34.1 \mathrm{~Hz}\right)$ and an additional $\mathrm{H}-\mathrm{C}$ coupling for the hydride signal (quintet of $\mathrm{d}$, ${ }^{2} \mathrm{~J}(\mathrm{CH})=4.5 \mathrm{~Hz}$ ) in the ${ }^{\mathrm{l}} \mathrm{H}$ NMR spectrum. When $\mathrm{MeOH}-$ $\mathrm{d}_{4}$ was added to the solution of the starting acyl complex, the deuterated anal ogue $\left[\mathrm{Pd}_{2}(\mathrm{dppf})_{2}(u-\mathrm{D})(u-\mathrm{CO})\right] \mathrm{OT}$ s formed; three signals were observed in the ${ }^{31} \mathrm{P}\left\{{ }^{1} \mathrm{H}\right\}$ NMR spectrum in an intensity ratio of 1:1:1 due to the phosphorus-deuterium coupling (2J $(P D)=6.1 \mathrm{~Hz})$.

Synthesis of 7. A stream of $\mathrm{CO}$ was bubbled through a solution of [PdMe(NCMe)(dppf)]OTf (162 mg, $0.19 \mathrm{mmol})$ in $\mathrm{CH}_{2} \mathrm{Cl}_{2}(2 \mathrm{~mL})$ at $-60{ }^{\circ} \mathrm{C}$ for $10 \mathrm{~min}$, then ethene was substituted for $\mathrm{CO}$. After bubbling ethene for $1 \mathrm{~min}$, the resulting solution was allowed to warm to $-20^{\circ} \mathrm{C}$. After 20 min, evaporation of the solvent at $-20^{\circ} \mathrm{C}$ gave an orange solid residue that was washed with cold diethyl ether and $n$ pentane. Yield: $80 \%$. Anal. Calcd for $\mathrm{C}_{39} \mathrm{H}_{35} \mathrm{~F}_{3} \mathrm{FeO}_{4} \mathrm{P}_{2} \mathrm{PdS}$ : C, 53.17; $\mathrm{H}, 4.00$. Found: $\mathrm{C}, 52.65 ; \mathrm{H}, 4.19 .{ }^{31} \mathrm{P}\left\{{ }^{1} \mathrm{H}\right\} \mathrm{NMR}\left(\mathrm{CD}_{2-}\right.$ $\mathrm{Cl}_{2},-20^{\circ} \mathrm{C}$ ): $\delta 38.7\left(\mathrm{~d},{ }^{2} \mathrm{~J}(\mathrm{PP})=35.7 \mathrm{~Hz}\right), 15.8(\mathrm{~d}) .{ }^{1} \mathrm{H} \mathrm{NMR}$ $\left(\mathrm{CD}_{2} \mathrm{Cl}_{2},-20{ }^{\circ} \mathrm{C}\right): \delta 7.8-7.3\left(\mathrm{~m}, 2 \mathrm{H}, \mathrm{Ar}-\mathrm{PPh}_{2}\right), 4.65(\mathrm{~m}, 2 \mathrm{H}$, $\mathrm{Cp}), 4.56(\mathrm{~m}, 2 \mathrm{H}, \mathrm{Cp}), 4.36(\mathrm{~m}, 2 \mathrm{H}, \mathrm{Cp}), 3.79(\mathrm{~m}, 2 \mathrm{H}, \mathrm{Cp}), 3.19$ $\left(\mathrm{dt}, 3 \mathrm{~J}(\mathrm{HH})=6.2 \mathrm{~Hz}\right.$, 光 $\left.(\mathrm{HP})=7.8 \mathrm{~Hz}, 2 \mathrm{H}, \mathrm{PdCH}_{2} \mathrm{CH}_{2}\right), 2.31$ $\left(\mathrm{s}, 3 \mathrm{H}, \mathrm{C}(\mathrm{O}) \mathrm{CH}_{3}\right), 1.39$ (dtd, 3 $(\mathrm{HH})=6.2 \mathrm{~Hz}$, 3 $(\mathrm{HP})=7.4$, $\left.3.2 \mathrm{~Hz}, 2 \mathrm{H}, \mathrm{PdCH}{ }_{2} \mathrm{CH}_{2}\right) \cdot{ }^{13} \mathrm{C}\left\{{ }^{1} \mathrm{H}\right\} \mathrm{NMR}\left(\mathrm{CD}_{2} \mathrm{Cl}_{2},-20{ }^{\circ} \mathrm{C}\right): \delta$ $238.9\left(\mathrm{~d}, 4 \mathrm{~J}(\mathrm{CP})=12.6 \mathrm{~Hz}, \mathrm{C}(\mathrm{O}) \mathrm{CH}_{3}\right), 136-130(\mathrm{~m}, \mathrm{Ph}), 76-$ $69(\mathrm{~m}, \mathrm{Cp}), 52.5\left(\mathrm{~d}, 3 \mathrm{~J}(\mathrm{CP})=6.0 \mathrm{~Hz}, \mathrm{PdCH}_{2} \mathrm{CH}_{2}\right), 39.0(\mathrm{~d}$, 2) $\left.(\mathrm{CP})=85.2 \mathrm{~Hz}, \mathrm{PdCH}_{2} \mathrm{CH}_{2}\right), 28.9\left(\mathrm{~s}, \mathrm{C}(\mathrm{O}) \mathrm{CH}_{3}\right)$. IR $(\mathrm{KBr}$ pellet, $\mathrm{cm}^{-1}$ ): 1630 (CO).

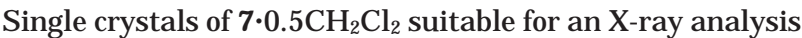
were obtained by crystallization from $\mathrm{CH}_{2} \mathrm{Cl}_{2} / \mathrm{Et}_{2} \mathrm{O}$ in a Schlenk tube stored at $-20{ }^{\circ} \mathrm{C}$. Anal. Calcd for $\mathrm{C}_{39} \mathrm{H}_{35} \mathrm{~F}_{3} \mathrm{FeO}_{4} \mathrm{P}_{2} \mathrm{PdS}$. $0.5 \mathrm{CH}_{2} \mathrm{Cl}_{2}$ : C, 51.37; $\mathrm{H}, 3.93$. Found: $\mathrm{C}, 51.02 ; \mathrm{H}, 3.89$.

Synthesis of 8. A solution of $7(52.8 \mathrm{mg}, 0.06 \mathrm{mmol})$ in $\mathrm{CD}_{2-}$ $\mathrm{Cl}_{2}(2 \mathrm{~mL})$ was maintained under a stream of $\mathrm{CO}$ at $-40{ }^{\circ} \mathrm{C}$ for $15 \mathrm{~min}$ and then transferred into a $5 \mathrm{~mm} \mathrm{NMR}$ tube at $-40{ }^{\circ} \mathrm{C}$. The tube was inserted into a NMR probe-head precooled at $-40{ }^{\circ} \mathrm{C} .{ }^{1} \mathrm{H}$ and ${ }^{31} \mathrm{P}\left\{{ }^{1} \mathrm{H}\right\} \mathrm{NMR}$ spectra showed the quantitative formation of the carbonyl acyl complex 8. ${ }^{31} \mathrm{P}\left\{{ }^{1} \mathrm{H}\right\}$ NMR $\left(\mathrm{CD}_{2} \mathrm{Cl}_{2},-40^{\circ} \mathrm{C}\right): \delta 23.0\left(\mathrm{~d},{ }^{2} \mathrm{~J}(\mathrm{PP})=62.1 \mathrm{~Hz}\right), 11.3(\mathrm{~d})$. ${ }^{1} \mathrm{H}$ NMR $\left(\mathrm{CD}_{2} \mathrm{Cl}_{2},-40^{\circ} \mathrm{C}\right): \delta 7.8-7.3\left(\mathrm{~m}, 2 \mathrm{H}, \mathrm{Ar}-\mathrm{PPh}_{2}\right), 4.77$ $(\mathrm{m}, 2 \mathrm{H}, \mathrm{Cp}), 4.66(\mathrm{~m}, 2 \mathrm{H}, \mathrm{Cp}), 4.34(\mathrm{~m}, 2 \mathrm{H}, \mathrm{Cp}), 3.70(\mathrm{~m}, 2 \mathrm{H}$, $\mathrm{Cp}), 2.56$ (br s, $2 \mathrm{H}, \mathrm{PdC}(\mathrm{O}) \mathrm{CH}_{2} \mathrm{CH}_{2}$ ), 2.12 (br s, 2H, $\mathrm{PdC}(\mathrm{O})$ $\left.\mathrm{CH}_{2} \mathrm{CH}_{2}\right), 1.97\left(\mathrm{~s}, 3 \mathrm{H}, \mathrm{C}(\mathrm{O}) \mathrm{CH}_{3}\right) \cdot{ }^{13} \mathrm{C}\left\{{ }^{1} \mathrm{H}\right\} \mathrm{NMR}\left(\mathrm{CD}_{2} \mathrm{Cl}_{2},-40\right.$ $\left.{ }^{\circ} \mathrm{C}\right): \delta 229.3\left(\mathrm{~d}, 2 \mathrm{~J}(\mathrm{CP})=86.7 \mathrm{~Hz}, \mathrm{PdC}(\mathrm{O}) \mathrm{CH}_{2}\right), 208.1(\mathrm{~s}$, $\left.\mathrm{CH}_{2} \mathrm{C}(\mathrm{O}) \mathrm{CH}_{3}\right), 177.0$ (br s, Pd(CO)), 136-130 (m, Ph), 78-69 $(\mathrm{m}, \mathrm{Cp}), 49.9\left(\mathrm{~m}, \mathrm{PdC}(\mathrm{O}) \mathrm{CH}_{2}\right), 39.6\left(\mathrm{~s}, \mathrm{CH}_{2} \mathrm{C}(\mathrm{O}) \mathrm{CH}_{3}\right), 30.2$ (s, $\left.\mathrm{C}(\mathrm{O}) \mathrm{CH}_{3}\right)$.

On using ${ }^{13} \mathrm{CO}$, the resonance at $\delta 11.3$ in the ${ }^{31} \mathrm{P}\left\{{ }^{1} \mathrm{H}\right\} \mathrm{NMR}$ spectrum became a doublet of doublets with ${ }^{2} \mathrm{f}(\mathrm{PC})=87.0 \mathrm{~Hz}$.

Synthesis of 9. Ethene was bubbled for $10 \mathrm{~min}$ through a solution of 7 ( $54.5 \mathrm{mg}, 0.06 \mathrm{mmol}$ ) obtained as above in $\mathrm{CD}_{2-}$ $\mathrm{Cl}_{2}(2 \mathrm{~mL})$ at $-60{ }^{\circ} \mathrm{C}$. A sample of the resulting solution (1 $\mathrm{mL}$ ) was transferred into a $5 \mathrm{~mm} \mathrm{NMR}$ tube at $-20^{\circ} \mathrm{C}$, and the tube was inserted into a NMR probe-head precooled at -20 ${ }^{\circ} \mathrm{C}$. A nother sample of the solution was transferred into a $\mathrm{KBr}$ cell for IR measurements. ${ }^{1} \mathrm{H},{ }^{13} \mathrm{C}\left\{{ }^{1} \mathrm{H}\right\}$, and ${ }^{31} \mathrm{P}\left\{{ }^{1} \mathrm{H}\right\} \mathrm{NMR}$ and IR spectra showed the quantitative formation of $9 .{ }^{31} \mathrm{P}\left\{{ }^{1} \mathrm{H}\right\}$ $\operatorname{NMR}\left(\mathrm{CD}_{2} \mathrm{Cl}_{2},-20^{\circ} \mathrm{C}\right): \delta 39.1\left(\mathrm{~d},{ }^{2} \mathrm{~J}(\mathrm{PP})=35.9 \mathrm{~Hz}\right), 15.1(\mathrm{~d})$. ${ }^{1} \mathrm{H} N M R\left(\mathrm{CD}_{2} \mathrm{Cl}_{2},-20^{\circ} \mathrm{C}\right): \delta 7.8-7.3\left(\mathrm{~m}, 2 \mathrm{H}, \mathrm{Ar}-\mathrm{PPh}_{2}\right), 4.65$ $(\mathrm{m}, 2 \mathrm{H}, \mathrm{Cp}), 4.56(\mathrm{~m}, 2 \mathrm{H}, \mathrm{Cp}), 4.34(\mathrm{~m}, 2 \mathrm{H}, \mathrm{Cp}), 3.79(\mathrm{~m}, 2 \mathrm{H}$, $\mathrm{Cp}), 3.18(\mathrm{dt}, 3 \mathrm{H}(\mathrm{HH})=6.6 \mathrm{~Hz}, 4 \mathrm{~J}(\mathrm{HP})=7.7 \mathrm{~Hz}, 2 \mathrm{H}$, $\left.\mathrm{PdCH}_{2} \mathrm{CH}_{2}\right), 2.87\left(\mathrm{t}, 3 \mathrm{~J}(\mathrm{HH})=5.6 \mathrm{~Hz}, 2 \mathrm{H}, \mathrm{C}(\mathrm{O}) \mathrm{CH}_{2} \mathrm{CH}_{2}\right), 2.31$ $\left(\mathrm{t}, 3 \mathrm{~J}(\mathrm{HH})=5.6 \mathrm{~Hz}, 2 \mathrm{H}, \mathrm{C}(\mathrm{O}) \mathrm{CH}_{2} \mathrm{CH}_{2}\right), 1.64\left(\mathrm{~s}, 3 \mathrm{H}, \mathrm{C}(\mathrm{O}) \mathrm{CH}_{3}\right)$, $1.56\left(t d d, 3 \mathrm{~J}(\mathrm{HH})=6.3 \mathrm{~Hz}, 3 \mathrm{~J}(\mathrm{HP})=7.4,2.7 \mathrm{~Hz}, 2 \mathrm{H}, \mathrm{PdCH}_{2}\right)$. ${ }^{13} \mathrm{C}\left\{{ }^{1} \mathrm{H}\right\} \mathrm{NMR}\left(\mathrm{CD}_{2} \mathrm{Cl}_{2},-20^{\circ} \mathrm{C}\right): \delta 239.4\left(\mathrm{dd},{ }^{3} \mathrm{~J}(\mathrm{CP})=12.8\right.$, $\left.1.3 \mathrm{~Hz}, \mathrm{CH}_{2} \mathrm{C}(\mathrm{O}) \mathrm{CH}_{2}\right), 207.2\left(\mathrm{~s}, \mathrm{CH}_{2} \mathrm{C}(\mathrm{O}) \mathrm{CH}_{3}\right), 135-123(\mathrm{~m}$, $\mathrm{Ph}$ ), 78-71 (m, Cp), 51.6 (d, 3) (CP) =6.0 Hz, $\left.\mathrm{PdCH}_{2} \mathrm{CH}_{2}\right), 39.2$ $\left(d\right.$, 2) (CP) $\left.=86.0 \mathrm{~Hz}, \mathrm{PdCH}_{2} \mathrm{CH}_{2}\right), 37.5\left(\mathrm{~s}, \mathrm{CH}_{2} \mathrm{CH}_{2} \mathrm{C}(\mathrm{O}) \mathrm{CH}_{3}\right)$, 34.7 ( $\left.\mathrm{s}, \mathrm{CH}_{2} \mathrm{C}(\mathrm{O}) \mathrm{CH}_{3}\right), 30.0$ (s, $\left.\mathrm{C}(\mathrm{O}) \mathrm{CH}_{3}\right)$. IR $\left(\mathrm{CD}_{2} \mathrm{Cl}_{2}, \mathrm{~cm}^{-1}\right)$ : $v(\mathrm{CO})$ 1629, 1710.

Stability Study of 2 in Methanol by NMR Spectroscopy. Synthesis and Characterization of $\mathbf{1 0}$. The starting solutions employed in this study were obtained by dissolving samples of 2 (8 mg, $0.007 \mathrm{mmol})$ in $\mathrm{MeOH}-\mathrm{d}_{4}(1 \mathrm{~mL})$ at room temperature. A $5 \mathrm{~mm} \mathrm{NMR}$ tube was charged under nitrogen with one of these solutions and then placed into the NMR probe at room temperature. The reaction was followed by ${ }^{31} \mathrm{P}$. $\left\{{ }^{1} \mathrm{H}\right\}$ and ${ }^{1} \mathrm{H} N M R$ spectroscopy. The results of this investigation are discussed in a previous section. NMR data for $\mathbf{2}$ ${ }^{31} \mathrm{P}\left\{{ }^{1} \mathrm{H}\right\} \mathrm{NMR}\left(\mathrm{MeOH}-\mathrm{d}_{4}, 20^{\circ} \mathrm{C}\right): \delta 71.6$ (s). ${ }^{1} \mathrm{H} \mathrm{NMR}(\mathrm{MeOH}-$ $\left.\mathrm{d}_{4}, 20^{\circ} \mathrm{C}\right): \delta 6.9-8.3\left(\mathrm{~m}, 28 \mathrm{H}, \mathrm{Ar}-\mathrm{PPh}_{2}+\mathrm{Ar}-\mathrm{OTs}\right), 2.23(\mathrm{~s}$, 6H, Me-OTs), 1.49 (s, 12H, Me-Cp*), 1.32 (s, 12H, Me-Cp*).

NMR data for 10: ${ }^{31} \mathrm{P}\left\{{ }^{1} \mathrm{H}\right\} \mathrm{NMR}\left(\mathrm{MeOH}-\mathrm{d}_{4}, 20^{\circ} \mathrm{C}\right): \delta-1.3$ (s). ${ }^{1} \mathrm{H}$ NMR (MeOH- $\left.\mathrm{d}_{4}, 20^{\circ} \mathrm{C}\right): 8.3-6.9\left(\mathrm{~m}, 48 \mathrm{H}, \mathrm{Ar}^{-\mathrm{PPh}_{2}+}\right.$ Ar-OTs), 2.23 (s, 6H, Me-OTs), 1.86 (br s, 24H, Me-Cp*), 0.51 (br s, $24 \mathrm{H}, \mathrm{Me}-\mathrm{Cp} *) .{ }^{31 \mathrm{P}}\left\{{ }^{1} \mathrm{H}\right\} \mathrm{NMR}\left(\mathrm{MeOH}-\mathrm{d}_{4},-40{ }^{\circ} \mathrm{C}\right)$ : $\delta-1.4(\mathrm{~s}) .{ }^{1} \mathrm{H}$ NMR $\left(-40{ }^{\circ} \mathrm{C}, \mathrm{MeOH}-\mathrm{d}_{4}\right): 8.3-6.9(\mathrm{~m}, 48 \mathrm{H}, \mathrm{Ar}-$ $\mathrm{PPh}_{2}+\mathrm{Ar}-\mathrm{OTs}$ ), 2.22 (s, 6H, Me-OTs), 1.87 (s, 24H, Me-Cp*), 0.50 (s, 24H, Me-Cp*).

In Situ HPNMR Study of the Methoxycarbonylation of Ethene Catalyzed by 2. A $10 \mathrm{~mm}$ sapphire HPNMR tube was charged under nitrogen with a solution of $\mathbf{2}(15 \mathrm{mg}, 0.013$ $\mathrm{mmol})$ in $\mathrm{MeOH}-\mathrm{d}_{4}(2 \mathrm{~mL})$ and then pressurized with a 1:1 mixture of $\mathrm{CO} / \mathrm{C}_{2} \mathrm{H}_{4}$ to 40 bar at room temperature. $\mathrm{TsOH}$ (10 mg, $0.052 \mathrm{mmol}, 4$ equiv) and/or BQ (23 mg, $0.208 \mathrm{mmol}, 16$ equiv), if any, were also added. The reactions were followed by variable-temperature ${ }^{31} \mathrm{P}\left\{{ }^{1} \mathrm{H}\right\}$ and ${ }^{1} \mathrm{H}$ NMR spectroscopy. Selected ${ }^{31} \mathrm{P}\left\{{ }^{1} \mathrm{H}\right\}$ NMR spectra are reported in Figures 3 and 4.

Synthesis of 4. A. A solution of $\mathbf{2}(150 \mathrm{mg}, 0.13 \mathrm{mmol})$ in $\mathrm{CH}_{2} \mathrm{Cl}_{2}(20 \mathrm{~mL})$ was introduced into a $100 \mathrm{~mL}$ autoclave and pressurized with $\mathrm{CO}$ to $20 \mathrm{bar}$ at room temperature. After 2 $\mathrm{h}$, the unreacted gas was released and the contents were transferred into a round-bottomed flask and concentrated to half of the volume under vacuum. The solution was filtered over Celite to eliminate black palladium, and a 3:1 mixture of $\mathrm{n}$-hexane/diethyl ether $(10 \mathrm{~mL})$ was added to precipitate the product, which was collected on a sintered-glass frit, washed with $\mathrm{n}$-hexane, and dried under a stream of nitrogen. Yield: $75 \%$

B. A solution of $2(150 \mathrm{mg}, 0.13 \mathrm{mmol})$ and $\mathrm{TsOH}(100 \mathrm{mg}$, $0.52 \mathrm{mmol}$ ) in $\mathrm{MeOH}(20 \mathrm{~mL})$ was introduced into a $100 \mathrm{~mL}$ autoclave and pressurized with $1: 1 \mathrm{CO} / \mathrm{C}_{2} \mathrm{H}_{4}$ to 40 bar at room temperature. After $30 \mathrm{~min}$, the unreacted gases were released and the contents was concentrated to dryness under vacuum. The solid residue was dissolved in THF and filtered over Celite to give an organic phase that was concentrated again to dryness. The solid residue was washed with n-pentane, filtered off, and dried under a stream of nitrogen. Yield: $60 \%$. Anal. Calcd for $\mathrm{C}_{92} \mathrm{H}_{96} \mathrm{Fe}_{2} \mathrm{O}_{4} \mathrm{P}_{4} \mathrm{Pd}_{2} \mathrm{~S}$ : C, 63.28; $\mathrm{H}$, 5.54. Found: $\mathrm{C}$, 63.14; $\mathrm{H}, 5.51 .{ }^{31} \mathrm{P}\left\{{ }^{1} \mathrm{H}\right\}$ NMR $\delta:\left(\mathrm{CD}_{2} \mathrm{Cl}_{2}, 20^{\circ} \mathrm{C}\right) 23.7$ (s); (THF$\left.\mathrm{d}_{8}, 20^{\circ} \mathrm{C}\right) 22.2$ (s); (THF- $\left.\mathrm{d}_{8},-70^{\circ} \mathrm{C}\right) 27.3\left(\mathrm{~d},{ }^{2} \mathrm{~J}(\mathrm{PP})=36.1\right.$

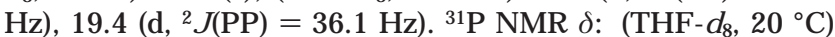
$22.2\left(\mathrm{~d},{ }^{2} \mathrm{~J}(\mathrm{PH})=40.1 \mathrm{~Hz}\right) ;\left(\mathrm{THF}-\mathrm{d}_{8},-70{ }^{\circ} \mathrm{C}\right) 27.3(\mathrm{dd}$, 2) $(P P)=36.1 \mathrm{~Hz}$, 2 $(\mathrm{PH})=82.1 \mathrm{~Hz}), 19.4\left(\mathrm{~d},{ }^{2} \mathrm{~J}(\mathrm{PP})=36.1\right.$ $\mathrm{Hz}) .{ }^{1} \mathrm{H}$ NMR $\delta:\left(\mathrm{CD}_{2} \mathrm{Cl}_{2}, 20^{\circ} \mathrm{C}\right)$ 8.1-6.8 (m, 44H, $\mathrm{Ar}-\mathrm{PPh}_{2}+$ Ar-OTs), 2.36 (s, 3H, Me-OTs), 1.62 (s, 24H, Me-Cp*), 1.25 (s, $24 \mathrm{H}, \mathrm{Me}-\mathrm{Cp} *$ ), -6.18 (quintet, $2 \mathrm{~J}(\mathrm{HP})=42.4 \mathrm{~Hz}, 1 \mathrm{H}, \mu-\mathrm{H}$ );

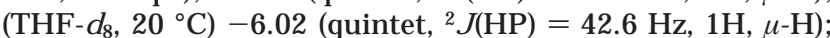
$\left(\mathrm{THF}-\mathrm{d}_{8},-70^{\circ} \mathrm{C}\right)-5.72\left(\mathrm{tt},{ }^{2} \mathrm{~J}(\mathrm{HP})=80.8,5.2 \mathrm{~Hz}, 1 \mathrm{H}, \mu-\mathrm{H}\right)$. ${ }^{13} \mathrm{C}\left\{{ }^{1} \mathrm{H}\right\}$ NMR $\left(\mathrm{CD}_{2} \mathrm{Cl}_{2}\right): \delta\left(20^{\circ} \mathrm{C}\right) 226.4$ (quintet, ${ }^{2} \mathrm{~J}(\mathrm{CP})=34.1$ $\mathrm{Hz}, \mu$-CO). IR (Nujol mull, $\mathrm{KBr}$ plates $/ \mathrm{CH}_{2} \mathrm{Cl}_{2}, \mathrm{~cm}^{-1}$ ): $v(\mathrm{CO})$ $1848 / 1846$. 
NMR experiments in $\mathrm{MeOH}-\mathrm{d}_{4}$ showed $\mathbf{4}$ to decompose into $\mathbf{2}$ and several unknown species when treated with $\mathrm{TsOH}$ or BQ.

Synthesis of 11. A $10 \mathrm{~mm}$ sapphire HPNMR tube was charged under nitrogen with a solution of 2 (15 mg, 0.013 mmol) in $\mathrm{MeOH}-\mathrm{d}_{4}(2 \mathrm{~mL})$ and pressurized to 40 bar with 1:1 $\mathrm{CO} / \mathrm{C}_{2} \mathrm{H}_{4}$ at room temperature. The tube was introduced into a spectrometer and heated to $40{ }^{\circ} \mathrm{C}$. The first spectrum acquired at this temperature showed the presence of the $\mathbf{1 1}$. The tube was removed from the probe-head, frozen in liquid nitrogen, and subjected to high vacuum. To the frozen sol ution was added 1 equiv of $\mathrm{TsOH}$. This mixture was allowed to thaw and reach room temperature. The formation of the $\mu$-hydride, $\mu$-CO complex 4 was determined by NMR spectroscopy. ${ }^{31} \mathrm{P}$ $\left\{{ }^{1} \mathrm{H}\right\} \mathrm{NMR}\left(\mathrm{MeOH}-\mathrm{d}_{4}, 20{ }^{\circ} \mathrm{C}\right): \delta 5.6(\mathrm{~s}) .{ }^{1} \mathrm{H} \mathrm{NMR}\left(\mathrm{MeOH}-\mathrm{d}_{4}\right.$, $\left.40{ }^{\circ} \mathrm{C}\right): \delta 7.9-7.0\left(\mathrm{~m}, 40 \mathrm{H}, \mathrm{Ar}-\mathrm{PPh}_{2}\right), 1.62(\mathrm{~s}, 24 \mathrm{H}, \mathrm{Me}-\mathrm{Cp} *)$, 1.11 (s, 24H, Me-Cp*).

Synthesis of 12. A $10 \mathrm{~mm}$ sapphire HPNMR tube was charged under nitrogen with a solution of 2 (15 mg, 0.013 $\mathrm{mmol})$ in $\mathrm{MeOH}-\mathrm{d}_{4}(2 \mathrm{~mL})$ and pressurized to 10 bar with $\mathrm{CO}$ at room temperature. ${ }^{1} \mathrm{H}$ and ${ }^{11} \mathrm{P}\left\{{ }^{1} \mathrm{H}\right\}$ NMR spectra showed the quantitative formation of $\mathbf{1 2}$. On standing at room temperature, this complex slowly undergoes methanolysis $\left(t_{1 / 2}=\right.$ $12 \mathrm{~h}$ ), decomposing to 4 and dimethyl carbonate- $\mathrm{d}_{6}$ (GC/MS analysis). Attempts to isolate $\mathbf{1 2}$ failed due to its decomposition to $\mathbf{2}$ when the $\mathrm{CO}$ pressure was released and nitrogen was added. ${ }^{31} \mathrm{P}\left\{{ }^{1} \mathrm{H}\right\} \mathrm{NMR}\left(\mathrm{MeOH}-\mathrm{d}_{4}, 20^{\circ} \mathrm{C}\right): \delta-19.1$ (s). ${ }^{1} \mathrm{H}$ NMR $\left(\mathrm{MeOH}-\mathrm{d}_{4}, 20^{\circ} \mathrm{C}\right): \delta 8.1-6.9\left(\mathrm{~m}, 24 \mathrm{H}, \mathrm{Ar}-\mathrm{PPh}_{2}+\mathrm{Ar}-\mathrm{OTs}\right)$, 2.28 (s, 3H, Me-OTs), 1.71 (s, 12H, Me-Cp*), 0.84 (s, 12H, MeCp*). ${ }^{13} \mathrm{C}\left\{{ }^{1} \mathrm{H}\right\}$ NMR $\left(\mathrm{MeOH}-\mathrm{d}_{4}, 20{ }^{\circ} \mathrm{C}\right): \delta 209.9$ (br s, C(O)$\left.\mathrm{OCD}_{3}\right)$.

Synthesis of 13. To a solution of dppomf (292 mg, 0.438 $\mathrm{mmol})$ in THF (30 mL) was added a solution of $\mathrm{PdCl}(\mathrm{Me})(\mathrm{COD})$ (116 mg, $0.439 \mathrm{mmol}$ ) under stirring. After $15 \mathrm{~min}$, the solution was concentrated to half volume and $\mathrm{n}$-hexane $(15 \mathrm{~mL})$ was added. The formed yellow solid was filtered off, washed with n-hexane, and dried in a stream of nitrogen. Yield: $86 \%$. Anal. Calcd for $\mathrm{C}_{43} \mathrm{H}_{47} \mathrm{CIFeP}_{2} \mathrm{Pd}$ : C, 62.72; $\mathrm{H}, 5.75$. Found: $\mathrm{C}, 62.70$; $\mathrm{H}$, 5.69. ${ }^{31} \mathrm{P}\left\{{ }^{1} \mathrm{H}\right\} N M R\left(\mathrm{CD}_{2} \mathrm{Cl}_{2}, 20{ }^{\circ} \mathrm{C}\right): \delta 45.2\left(\mathrm{~d},{ }^{2} \mathrm{~J}(\mathrm{PP})=\right.$ $24.5 \mathrm{~Hz}), 12.8(\mathrm{~d}) .{ }^{1} \mathrm{H} N M R\left(\mathrm{CD}_{2} \mathrm{Cl}_{2}, 20^{\circ} \mathrm{C}\right): \delta 8.3-7.2(\mathrm{~m}, 20 \mathrm{H}$, $\mathrm{Ar}_{-\mathrm{PPh}}$ ), 1.56 (s, 6H, Cp*), $1.52(\mathrm{~s}, 6 \mathrm{H}, \mathrm{Cp} *), 1.28(\mathrm{~s}, 6 \mathrm{H}, \mathrm{Cp} *)$, 1.10 (s, 6H, Cp*), 0.96 (dd, 3) (HP) = 7.0, 3.8 Hz, 3H, Me).

Synthesis of 14. To a solution of $13(150 \mathrm{mg}, 0.182 \mathrm{mmol})$ in $\mathrm{CH}_{2} \mathrm{Cl}_{2}(10 \mathrm{~mL})$ was added AgOTs $(51 \mathrm{mg}, 0.182 \mathrm{mmol})$. After the resulting mixture was stirred overnight, it was filtered over Celite and the filtrate was concentrated to $5 \mathrm{~mL}$. Addition of $\mathrm{Et}_{2} \mathrm{O}$ caused the precipitation of a yellow microcrystalline solid, which was filtered off, washed with $\mathrm{Et}_{2} \mathrm{O}$, and dried in a vacuum. Yield: $87 \%$. Anal. Calcd for $\mathrm{C}_{50} \mathrm{H}_{56} \mathrm{FeO}_{4} \mathrm{P}_{2^{-}}$ PdS: C, 61.45; $\mathrm{H}, 5.78$. Found: $\mathrm{C}, 61.38 ; \mathrm{H}, 5.79 .{ }^{31} \mathrm{P}\left\{{ }^{1} \mathrm{H}\right\} \mathrm{NMR}$ $\left(\mathrm{CD}_{2} \mathrm{Cl}_{2}\right):\left(20^{\circ} \mathrm{C}\right) \delta 48.8(\mathrm{br}), 12.6\left(\mathrm{~d},{ }^{2} \mathrm{~J}(\mathrm{PP})=20.5 \mathrm{~Hz}\right) ;(-80$ $\left.{ }^{\circ} \mathrm{C}\right) \delta 50.8\left(\mathrm{~d},{ }^{2} \mathrm{~J}(\mathrm{PP})=24.6 \mathrm{~Hz}\right), 12.7$ (d). ${ }^{1} \mathrm{H}$ NMR $\left(\mathrm{CD}_{2} \mathrm{Cl}_{2}, 20\right.$ $\left.{ }^{\circ} \mathrm{C}\right): \delta 8.2-6.7\left(\mathrm{~m}, 24 \mathrm{H}, \mathrm{Ar}^{-\mathrm{PPh}_{2}}+\mathrm{Ar}-\mathrm{OTs}\right), 1.55$ (s, 12H, Cp*), $1.28(\mathrm{~s}, 6 \mathrm{H}, \mathrm{Cp} *), 1.12(\mathrm{~s}, 6 \mathrm{H}, \mathrm{Cp} *), 0.88$ (br t, 3) (HP) = 6.4 $\mathrm{Hz}, 3 \mathrm{H}, \mathrm{Me}$ ). This complex behaves as a 1:1 electrolyte in both $\mathrm{CH}_{2} \mathrm{Cl}_{2}\left(\Lambda_{\mathrm{M}}: 8 \Omega^{-1} \mathrm{~cm}^{2} \mathrm{~mol}^{-1}\right)$ and nitroethane $\left(\Lambda_{\mathrm{M}}: 38 \Omega^{-1}\right.$ $\left.\mathrm{cm}^{2} \mathrm{~mol}^{-1}\right) \cdot{ }^{32}$

Reaction of 14 with CO: Synthesis of 15. Carbon monoxide was bubbled for 5 min through a solution of $\mathbf{1 4}$ (15 $\mathrm{mg}, 0.015 \mathrm{mmol})$ in $\mathrm{CD}_{2} \mathrm{Cl}_{2}(1.5 \mathrm{~mL})$ at $0{ }^{\circ} \mathrm{C}$. A $1 \mathrm{~mL}$ sample of the resultant solution was transferred by syringe into a 5 $\mathrm{mm} N M R$ tube at room temperature. ${ }^{1} \mathrm{H}$ and ${ }^{31} \mathrm{P}\left\{{ }^{1} \mathrm{H}\right\} N M R$ spectra showed the quantitative formation of 15. ${ }^{31} \mathrm{P}\left\{{ }^{1} \mathrm{H}\right\} N M R$ $\left(\mathrm{CD}_{2} \mathrm{Cl}_{2}, 20^{\circ} \mathrm{C}\right): \delta-13.3(\mathrm{~s}) .{ }^{1} \mathrm{H}$ NMR $\left(\mathrm{CD}_{2} \mathrm{Cl}_{2}, 20^{\circ} \mathrm{C}\right): \delta 7.8-$ $7.0\left(\mathrm{~m}, 24 \mathrm{H}, \mathrm{Ar}-\mathrm{PPh}_{2}+\mathrm{Ar}-\mathrm{OTs}\right), 3.09(\mathrm{t}, 4 \mathrm{~J}(\mathrm{HP})=1.7 \mathrm{~Hz}, 3 \mathrm{H}$,
Me), 2.31 (s, 3H, Me-OTs), 1.74 (s, 12H, MeCp*), 1.21 (s, 12H, Me-Cp*).

Reaction of 15 with MeOH. A solution of 15 in $\mathrm{CD}_{2} \mathrm{Cl}_{2}$ was prepared as above and transferred into a $5 \mathrm{~mm} \mathrm{NMR}$ tube equipped with a rubber cap. A $100 \mu \mathrm{L}$ sample of $\mathrm{MeOH}$ was injected by syringe into the tube at room temperature. ${ }^{1} \mathrm{H}$ and ${ }^{31} \mathrm{P}\left\{{ }^{1} \mathrm{H}\right\} N M R$ spectroscopy showed the formation of $\mathbf{4}$ and methyl acetate al ready in the first spectra.

Reaction of $\mathbf{1 5}$ with $\mathbf{C O} / \mathbf{C}_{\mathbf{2}} \mathbf{H}_{4}$. A $1: 1 \mathrm{CO} / \mathrm{C}_{2} \mathrm{H}_{4}$ mixture was bubbled for $15 \mathrm{~min}$ at room temperature into a $\mathrm{CD}_{2} \mathrm{Cl}_{2}$ solution of $\mathbf{1 5}$ in a $5 \mathrm{~mm}$ NMR tube equipped with a rubber cap. Then, the tube was closed and allowed to stand for $15 \mathrm{~min}$ at room temperature. A $100 \mu \mathrm{L}$ sample of $\mathrm{MeOH}$ was injected by syringe into the tube. ${ }^{1} \mathrm{H}$ and ${ }^{31} \mathrm{P}\left\{{ }^{1} \mathrm{H}\right\}$ NMR spectra showed the formation of $\mathbf{4}$ and methyl acetate. GC/MS confirmed the exclusive formation of methyl acetate.

X-ray Data Collection and Structure Determination of $\left[\mathrm{C}_{38} \mathrm{H}_{35} \mathrm{FeOP} \mathbf{P d}^{+}\right]\left[\mathrm{SO}_{3} \mathrm{CF}_{3}{ }^{-}\right] \cdot \mathbf{0 . 5}\left(\mathrm{CH}_{2} \mathrm{Cl}_{2}\right)$. X-ray data were collected at $150 \mathrm{~K}$ on an Enraf-Nonius TurboCAD4 (Rotating Anode, $\mathrm{MoK} \alpha, \theta \max =26.5^{\circ}$ ). Reflection profiles turned out to be broad and highly structured. Pertinent data: monoclinic, space group P2 $1 / C$ (No. 14), $a=11.057(2) \AA, b=$ 23.767(4) $\AA, \mathrm{C}=16.203(3) \AA, \beta=116.78(1)^{\circ}, \mathrm{Z}=4$. The structure was solved by direct methods (SIR97) ${ }^{34}$ and refined on $\mathrm{F}^{2}$ with SHELXL96 $6^{35}$ to a final $\mathrm{R}=0.0813$ for 3287 reflections with $\mathrm{I}>2 \sigma(\mathrm{I})$ [WR2 $=0.167$ for 7763 reflections]. The main cation structure contains two solvent-accessible voids at $0,1 / 2,0$ and $0,0,1 / 2$ of $419 \AA^{3}$, each containing disordered OTf- and $\mathrm{CH}_{2} \mathrm{Cl}_{2}$. Their contribution to the structure factors was taken into account by back-Fourier transformation using the PLATON/SQUEEZE ${ }^{36}$ procedure. A total of 189 electrons/ per void were accounted for (corresponding with two OTf- and one $\mathrm{CH}_{2} \mathrm{Cl}_{2}$ per void). Data were cor rected for absorption with the PLATON/DELABS ${ }^{36}$ procedure. Hydrogen atoms were taken into account at calculated positions and refined riding on their carrier atoms.

Acknowledgment. Thanks are due to the foll owing institutions: European Community (contracts HPRNCT-2000-00010 and HPRN-CT-2002-00196; COST ACtion D17 with the Working Groups 0007/2000 and 0002/ 2000); a CNR-RAS bilateral agreement; the Russian Foundation for Basic Research (Grants 00-03-32855 and 01-03-06145); Haldor Topsøe A/S (Denmark); the Shell Research and Technol ogy Centre, Amsterdam (M.A.Z.); the National Research School Combination Catalysis (Z.F.). A.L.S. wishes to thank The Netherlands F oundati on for Chemical Sciences (CW) with financial aid from the Netherlands Organization for Scientific Research (NWO).

Supporting Information Available: Tables of crystal data and collection parameters, bond lengths and angles, and positional and thermal parameters for compound $\mathbf{7 \cdot 0 . 5 \mathrm { CH } _ { 2 } -}$ $\mathrm{Cl}_{2}$. This material is available free of charge via the Internet at http://pubs.acs.org.

\section{OM021049B}

(33) Bianchini, C.; Meli, A.; Traversi, A. Ital. Pat. FI A000025, 1997. (34) Altomare, A.; Burla, M. C.; Camalli, M.; Cascarano, G. L.; Giacovazzo, C.; Guagliardi, A.; Moliterni, A. G. G.; Polidori, G.; Spagna, R. J . Appl. Crystallogr. 1999, 32, 115.

(35) Sheldrick, G. M. SHELXL 96 Program for Crystal Structure Refinement; University of Göttingen: Göttingen, Germany, 1996.

(36) Spek, A. L. Acta Crystallogr. 1990, A46, C34. 